\title{
Qualidade do emprego na agricultura brasileira no período 2001-2004 e suas diferenciações por culturas
}

\author{
Otavio Valentim Balsadi*
}

Resumo: A partir dos microdados da Pesquisa Nacional por Amostra de Domicílios (PNAD), o presente estudo analisou a qualidade do emprego na agricultura brasileira como um todo e, também, em seis culturas (arroz, café, cana-de-açúcar, mandioca, milho e soja) no período 2001-2004. Para a análise, foi construído um Índice de Qualidade de Emprego (IQE), composto por quatro dimensões: nível educacional dos empregados; grau de formalidade do emprego; rendimento recebido no trabalho principal; e auxílios recebidos pelos empregados. O IQE foi calculado para os empregados permanentes e para os empregados temporários, levando-se em consideração o local de moradia dos mesmos (urbano ou rural).

Palavras-chave: agricultura, emprego, Brasil.

Classificação JEL: J21, J23, J43.

Abstract: Based on the Nacional Households Survey (PNAD), this paper analyzed the employment quality in the Brazilian agriculture and six main crops (rice, coffee, sugarcane, manioc, corn and soybean) in the 2001-2004 period. An Employment Quality Index (EQI) was created for this analysis, based on four dimensions: level of education; degree of job

* Engenheiro Agrônomo, Doutor, Pesquisador da Empresa Brasileira de Pesquisa Agropecuária (Embrapa). otavio.balsadi@embrapa.br. 
formalization; main job income; and employee benefits. The EQI was calculated for the permanent and temporary workers, considering the local of the households (urban and rural).

Key words: agriculture, employment, Brazil.

JEL Classification: J21, J23, J43.

\section{Introdução}

Vistos pelo lado da agricultura, os primeiros anos do século XXI foram bastante favoráveis para este importante segmento da economia brasileira. Entre 2001 e 2004, a agricultura brasileira registrou taxas de crescimento bem superiores às observadas para a economia como um todo. Nesse período, sua participação no PIB passou de $8,4 \%$ para $10,1 \%$, tendo registrado um valor de $\mathrm{R} \$ 178,3$ bilhões no ano de 2004 (Tabela 1).

Tabela 1 - Produto Interno Bruto (PIB) da Agricultura, em Valores Reais Brasil, 2001-2004

\begin{tabular}{|c|c|c|c|c|}
\hline Categorias & 2001 & 2002 & 2003 & 2004 \\
\hline PIB Total & $1.642 .689 .556,12$ & $1.674 .393 .464,55$ & $1.683 .518 .152,41$ & $1.766 .621 .034,00$ \\
\hline Índice & 100 & 102 & 102 & 108 \\
\hline PIB Agricultura & $137.878 .474,39$ & $146.484 .764,33$ & $166.699 .644,20$ & $178.329 .440,33$ \\
\hline Participação (\%) & 8,4 & 8,7 & 9,9 & 10,1 \\
\hline Índice & 100 & 106 & 121 & 129 \\
\hline
\end{tabular}

Fonte: Instituto Brasileiro de Geografia e Estatística (IBGE).

Nota: Valores em Reais de 2004.

Vários fatores contribuíram para este bom desempenho: os efeitos positivos da desvalorização do Real ocorrida em 1999, que permitiu a recuperação das exportações brasileiras, incluindo as do agronegócio; os aumentos expressivos da área cultivada e da quantidade produzida de grãos e oleaginosas, com claro destaque para a soja; os ganhos de produtividade em todos os fatores de produção (terra, trabalho e capital); a recuperação dos preços internacionais de algumas commodities; o incremento no volume de recursos destinados ao crédito 
rural, especialmente os do Programa Nacional de Fortalecimento da Agricultura Familiar (Pronaf) ${ }^{1}$.

Quanto às exportações do agronegócio, pode-se notar que houve um aumento significativo das mesmas, principalmente no período posterior a 2002. Entre 2001 e 2004 houve um acréscimo de cerca de US\$15,1 bilhões no volume exportado, reforçando o papel do setor na obtenção dos saldos positivos da balança comercial brasileira (Tabela 2). Nesse período, sua participação média no total das exportações foi de 41,1\%.

Tabela 2 - Balança Comercial Total e do Agronegócio (em US\$ Milhões) Brasil, 2001-2004

\begin{tabular}{l|c|c|c|c|c|c|c|c}
\hline \multirow{2}{*}{ Anos } & \multicolumn{3}{|c|}{ Exportação } & \multicolumn{3}{c|}{ Importação } & \multicolumn{2}{c}{ Saldo } \\
\cline { 2 - 9 } & Total & Agronegócio & Part. (\%) & Total & Agronegócio & Part. (\%) & Total & Agronegócio \\
\hline $\mathbf{2 0 0 1}$ & $58.222,64$ & $23.863,22$ & 41,0 & $55.585,52$ & $4.847,19$ & 8,7 & $2.637,12$ & $19.016,03$ \\
$\mathbf{2 0 0 2}$ & $60.361,79$ & $24.838,89$ & 41,2 & $47.222,13$ & $4.491,60$ & 9,5 & $13.139,66$ & $20.347,29$ \\
$\mathbf{2 0 0 3}$ & $73.084,00$ & $30.639,00$ & 41,9 & $48.260,00$ & $4.791,00$ & 9,9 & $24.824,00$ & $25.848,00$ \\
$\mathbf{2 0 0 4}$ & $96.475,00$ & $39.016,00$ & 40,4 & $62.782,00$ & $4.881,00$ & 7,8 & $33.693,00$ & $34.135,00$ \\
\hline
\end{tabular}

Fonte: SECEX/MDIC.

Outro fator positivo associado ao bom desempenho da agricultura no período em questão, foi o aumento do número de empregados. Entre 2001 e 2004 houve um crescimento de 443,9 mil novos empregos (ou $10,4 \%)$. É importante notar que também melhorou o grau de formalidade do emprego na agricultura brasileira: em 2001, 28,1\% dos empregados tinham carteira assinada, valor que subiu para $32,3 \%$, em 2004 . No período analisado, houve aumento de $26,6 \%$, ou 320,4 mil empregados com registro em carteira (Tabela 3).

Houve crescimento do número dos empregados, e dos empregados formalizados, em todas as regiões do país. Os maiores aumentos relativos ocorreram nas regiões Sul e Nordeste, onde as variações foram de, respectivamente, $13,4 \%$ e 13,2\% no total de empregados. Quanto ao grau de formalidade, os maiores aumentos ocorreram nas regiões Norte Urbano $(102,4 \%)$ e Nordeste $(37,2 \%)$. No entanto, apesar desse

${ }^{1}$ Para uma análise mais detalhada destes temas, que fogem ao escopo do presente estudo, ver os trabalhos de Balsadi (2005); Brandão, Rezende e Marques (2005); Gasquez et al. (2004a); Gasquez et al. (2004b). 
desempenho, essas duas regiões eram, em 2004, as únicas com grau de formalidade abaixo da média nacional, que foi de $32,3 \%$. A maior participação de empregados com carteira assinada, em 2004, era a da região Sudeste, com 45,9\%, seguida pelo Centro-Oeste, com 39,3\% .

Tabela 3 - Total de Empregados na Agricultura Brasil, 2001-2004

\begin{tabular}{|c|c|c|c|c|c|c|}
\hline \multirow[b]{2}{*}{ Brasil } & \multirow[b]{2}{*}{2001} & \multirow[b]{2}{*}{2002} & \multirow[b]{2}{*}{2003} & \multirow[b]{2}{*}{2004} & \multicolumn{2}{|c|}{ Variação 2001-2004 } \\
\hline & & & & & Absoluta & Relativa (\%) \\
\hline Total de Empregados & 4.278 .439 & 4.466 .133 & 4.577 .850 & 4.722 .296 & 443.857 & 10,4 \\
\hline $\begin{array}{l}\text { Empregados com } \\
\text { Carteira }\end{array}$ & 1.202 .696 & 1.318 .664 & 1.373 .496 & 1.523 .127 & 320.431 & 26,6 \\
\hline Participação (\%) & 28,1 & 29,5 & 30,0 & 32,3 & 4,1 & 14,7 \\
\hline
\end{tabular}

Fonte: IBGE - Síntese de Indicadores da PNAD.

Em função desse cenário, o presente artigo tem por objetivo fazer uma análise mais detalhada desta categoria de ocupados na agricultura, os empregados. Torna-se relevante saber se nesse período bastante favorável houve também melhorias na qualidade do emprego na agricultura brasileira. A hipótese é que, pelo aumento do grau de formalidade e pelo forte crescimento de commodities com modernos sistemas de produção, houve melhorias na qualidade do emprego, embora deva ser ressaltada a possibilidade de comportamentos distintos para os empregados permanentes e para os empregados temporários, bem como para as distintas culturas que serão objeto do estudo.

\section{Procedimentos Metodológicos}

A fonte dos dados primários utilizados no estudo da população economicamente ativa (PEA) ocupada na agricultura é a Pesquisa Nacional por Amostra de Domicílios (PNAD), realizada pelo Instituto Brasileiro de Geografia e Estatística (IBGE). Para as atividades selecionadas, os dados referem-se ao trabalho único ou principal que as pessoas de 10 anos ou mais de idade tinham na semana de referência da pesquisa, normalmente a última ou a penúltima do mês de setembro.

Por PEA ocupada entende-se o conjunto de pessoas que tinham 
trabalho ${ }^{2}$ durante todo ou parte do período da semana de referência. Também fazem parte da PEA ocupada as pessoas que não exerceram o trabalho remunerado que tinham no período especificado, por motivo de férias, licenças, greves, entre outros (IBGE, 2004).

Quanto à posição na ocupação, a categoria que interessa para o presente estudo é a dos empregados (permanentes e temporários). Segundo as definições da PNAD, é considerado empregado a pessoa que trabalha para um empregador (pessoa física ou jurídica), geralmente obrigando-se ao cumprimento de uma jornada de trabalho e recebendo em contrapartida uma remuneração em dinheiro, mercadorias, produtos ou benefícios (IBGE 2004).

A Tabela 4 apresenta o número de casos que a PNAD captou para os empregados permanentes e temporários nos anos selecionados para análise, ou seja, 2001 e 2004. A expansão dessas amostras, a partir dos pesos de cada pessoa entrevistada na pesquisa, resulta no número de pessoas ocupadas, que é apresentado na Tabela 5.

Tabela 4 - Casos nas Amostras da PNAD para Empregado Permanente e Empregado Temporário, segundo a Área - Brasil e Grandes Regiões, 2001-2004

\begin{tabular}{l|rrrrr|r|r|r|r}
\hline \multirow{2}{*}{$\begin{array}{l}\text { Brasil e Grandes } \\
\text { Regiões }\end{array}$} & \multicolumn{3}{|c|}{ Empregado Permanente } & \multicolumn{3}{c}{ Empregado Temporário } \\
\cline { 2 - 10 } & \multicolumn{2}{c}{ Urbano } & \multicolumn{2}{c}{ Rural } & \multicolumn{2}{c}{ Urbano } & \multicolumn{2}{c}{ Rural } \\
\cline { 2 - 10 } & $\mathbf{2 0 0 1}$ & $\mathbf{2 0 0 4}$ & $\mathbf{2 0 0 1}$ & $\mathbf{2 0 0 4}$ & $\mathbf{2 0 0 1}$ & $\mathbf{2 0 0 4}$ & $\mathbf{2 0 0 1}$ & \multicolumn{2}{c}{$\mathbf{2 0 0 4}$} \\
\hline Centro-Oeste & 320 & 306 & 538 & 592 & 283 & 259 & 124 & 161 \\
Nordeste & 403 & 445 & 954 & 898 & 645 & 774 & 1.266 & 1.540 \\
Norte Urbano & 139 & 128 & - & - & 284 & 300 & - & - \\
Sudeste & 488 & 539 & 912 & 774 & 464 & 705 & 515 & 504 \\
Sul & 161 & 175 & 361 & 355 & 162 & 196 & 160 & 179 \\
\hline Total de Brasil & $\mathbf{1 . 5 1 1}$ & $\mathbf{1 . 5 9 3}$ & $\mathbf{2 . 7 6 5}$ & $\mathbf{2 . 6 1 9}$ & $\mathbf{1 . 8 3 8}$ & $\mathbf{2 . 2 3 4}$ & $\mathbf{2 . 0 6 5}$ & $\mathbf{2 . 3 8 4}$ \\
\hline
\end{tabular}

Fonte: Elaboração do Autor a partir dos microdados da PNAD.

\footnotetext{
${ }^{2} \mathrm{Na}$ PNAD, considera-se trabalho em atividade econômica o exercício de: a) ocupação remunerada em dinheiro, produtos, mercadorias ou benefícios (moradia, alimentação, roupas etc) na produção de bens e serviços; b) ocupação sem remuneração na produção de bens e serviços, desenvolvida durante pelo menos uma hora na semana (em ajuda a membro da unidade domiciliar que tivesse trabalho como conta própria, empregador ou empregado na produção de bens primários, que compreende as atividades da agricultura, silvicultura, pecuária, extração vegetal ou mineral, caça, pesca e piscicultura; como aprendiz ou estagiário ou em ajuda a instituição religiosa, beneficente ou de cooperativismo); c) ocupação desenvolvida, durante pelo menos uma hora na semana, na produção de bens do ramo que compreende as atividades da agricultura, silvicultura, pecuária, extração vegetal, pesca e piscicultura, para a própria alimentação de pelo menos um membro da unidade domiciliar.
} 
Tabela 5 - Pessoas Ocupadas na Semana de Referência na Condição de Empregado Permanente e Empregado Temporário, segundo a Área Brasil e Grandes Regiões, 2001-2004

\begin{tabular}{|c|c|c|c|c|c|c|c|c|}
\hline \multirow{3}{*}{$\begin{array}{l}\text { Brasil e } \\
\text { Grandes } \\
\text { Regiões }\end{array}$} & \multicolumn{4}{|c|}{ Empregado Permanente } & \multicolumn{4}{|c|}{ Empregado Temporário } \\
\hline & \multicolumn{2}{|c|}{ Urbano } & \multicolumn{2}{|c|}{ Rural } & \multicolumn{2}{|c|}{ Urbano } & \multicolumn{2}{|c|}{ Rural } \\
\hline & 2001 & 2004 & 2001 & 2004 & 2001 & 2004 & 2001 & 2004 \\
\hline entro-Oeste & 104.425 & 101.516 & 175.462 & 194.333 & 92.272 & 87.312 & 40.099 & 53.405 \\
\hline Nordeste & 185.436 & 209.897 & 460.754 & 43 & 306.805 & 375.667 & 608.025 & 748.732 \\
\hline Norte Urbano & 38.558 & 39.015 & - & & 79.972 & 92.987 & - & \\
\hline Sudeste & 322.481 & 362.378 & 537.448 & 464.127 & 302.786 & 484.127 & 295.790 & 291.542 \\
\hline Sul & 83.084 & 92.490 & 195.996 & 200.263 & 90.804 & 113.946 & 84.705 & 99.872 \\
\hline Total Brasil & 733.984 & 805.296 & 1.369 .660 & 1.298 .065 & 872.639 & 1.154 .039 & 1.028 .619 & 1.193 .551 \\
\hline
\end{tabular}

Fonte: Elaboração do Autor a partir dos microdados da PNAD.

É importante registrar que esse total de pessoas ocupadas pode divergir levemente dos valores divulgados pelo IBGE na Síntese de Indicadores. Isso porque nesse total só aparecem as pessoas para as quais existiam os dados utilizados na construção do Índice de Qualidade do Emprego, que será descrito a seguir. Ou seja, só estão computados os empregados, permanentes e temporários, para os quais os dados não eram missing.

Além da análise agregada para o total de Brasil (para a atividade agrícola como um todo), dado o número de casos presentes nas amostras das PNADs, será possível, também, a análise da qualidade do emprego para as seguintes culturas, que possuem individualização na classificação da CNAE: arroz, café, cana-de-açúcar, mandioca, milho e soja (Tabela 6). A expansão dessas amostras, a partir dos pesos de cada pessoa entrevistada na pesquisa, resulta no número de pessoas ocupadas por cultura, que é apresentado na Tabela 7 .

É importante salientar que estas amostras não englobam, necessariamente, todas as pessoas ocupadas nestas culturas, pois a PNAD mantém, em sua classificação, um grupo de resíduo (outras atividades) e um outro com a denominação de culturas diversas, os quais também podem conter pessoas ocupadas nas atividades selecionadas. Nestas amostras aparecem apenas as pessoas ocupadas que na entrevista responderam claramente em qual atividade encaixava-se o seu trabalho principal na semana de referência da pesquisa. Portanto, de acordo com os dados obtidos pela expansão destas amostras da PNAD, não é possí- 
vel avaliar, exatamente, o número de pessoas ocupadas nestas atividades, nem tampouco seu crescimento ou decréscimo quando comparado a outros anos em que a pesquisa foi realizada. E, este também não é o objetivo do presente estudo.

Tabela 6 - Casos nas Amostras da PNAD para Empregado Permanente e Empregado Temporário, segundo a Área e a Cultura - Brasil, 2001-2004

\begin{tabular}{l|rrrrr|rrr|r|r}
\hline \multirow{3}{*}{ Culturas } & \multicolumn{2}{|c|}{ Empregado Permanente } & \multicolumn{3}{c}{ Empregado Temporário } \\
\cline { 2 - 10 } & \multicolumn{2}{c}{ Urbano } & \multicolumn{2}{c}{ Rural } & \multicolumn{2}{c}{ Urbano } & \multicolumn{2}{c}{ Rural } \\
\cline { 2 - 10 } & $\mathbf{2 0 0 1}$ & $\mathbf{2 0 0 4}$ & $\mathbf{2 0 0 1}$ & $\mathbf{2 0 0 4}$ & $\mathbf{2 0 0 1}$ & $\mathbf{2 0 0 4}$ & $\mathbf{2 0 0 1}$ & $\mathbf{2 0 0 4}$ \\
\hline Arroz & 18 & 34 & 46 & 43 & 36 & 72 & 20 & 66 \\
Café & 105 & 105 & 338 & 234 & 195 & 257 & 208 & 208 \\
Cana-de-Açúcar & 193 & 237 & 198 & 221 & 208 & 270 & 151 & 158 \\
Mandioca & 24 & 39 & 34 & 51 & 80 & 143 & 180 & 234 \\
Milho & 49 & 37 & 80 & 69 & 145 & 127 & 248 & 272 \\
Soja & 62 & 103 & 81 & 171 & 41 & 69 & 24 & 36 \\
\hline
\end{tabular}

Fonte: Elaboração do Autor a partir dos microdados da PNAD.

Tabela 7 - Pessoas Ocupadas na Semana de Referência na Condição de Empregado Permanente e Empregado Temporário, segundo a Área e a Cultura Brasil, 2001-2004

\begin{tabular}{l|c|c|c|c|c|c|c|c}
\hline \multirow{3}{*}{ Culturas } & \multicolumn{3}{c|}{ Empregado Permanente } & \multicolumn{3}{c}{ Empregado Temporário } \\
\cline { 2 - 9 } & \multicolumn{2}{c}{ Urbano } & \multicolumn{2}{c}{ Rural } & \multicolumn{2}{c}{ Urbano } & \multicolumn{2}{c}{ Rural } \\
\cline { 2 - 9 } & $\mathbf{2 0 0 1}$ & $\mathbf{2 0 0 4}$ & $\mathbf{2 0 0 1}$ & $\mathbf{2 0 0 4}$ & $\mathbf{2 0 0 1}$ & $\mathbf{2 0 0 4}$ & $\mathbf{2 0 0 1}$ & $\mathbf{2 0 0 4}$ \\
\hline Arroz & 8.092 & 15.971 & 22.884 & 20.769 & 13.257 & 33.550 & 11.308 & 36.185 \\
Café & 56.183 & 58.631 & 183.730 & 130.520 & $106.851,0$ & 148.516 & 108.527 & 109.861 \\
Cana-de-Açúcary & 115.186 & 139.044 & 98.455 & 112.436 & $118.108,0$ & 166.026 & 74.563 & 75.656 \\
Mandioca & 11.527 & 16.287 & 15.201 & 22.943 & 40.177 & 68.573 & 85.577 & 112.117 \\
Milho & 26.503 & 17.816 & 44.183 & 35.245 & 70.204 & 60.418 & 128.878 & 137.661 \\
Soja & 25.636 & 43.255 & 34.669 & 74.557 & 19.739 & 32.406 & 10.865 & 15.917 \\
\hline
\end{tabular}

Fonte: Elaboração do Autor a partir dos microdados da PNAD.

Como pode ser observado nas tabelas anteriores, os dados estão desagregados para as áreas rurais e urbanas, de acordo com o local de moradia dos empregados permanentes e temporários. A classificação da situação do domicílio (urbana ou rural) é feita segundo a área de localização do mesmo e tem por base a legislação vigente por ocasião da realização do Censo Demográfico de 2001. 
Legalmente, a agregação oficial dos dados em urbano e rural, por ocasião da realização dos Censos Demográficos, segue o que é definido pelos próprios municípios. Como situação urbana consideram-se as áreas correspondentes às cidades (sedes municipais), às vilas (sedes distritais) e às áreas urbanas não urbanizadas. A situação rural abrange toda a área situada fora desses limites. Este critério também é utilizado na classificação das populações em urbana e rural.

Para a análise da qualidade do emprego na agricultura brasileira foi construído um Índice de Qualidade do Emprego (IQE), baseado na metodologia desenvolvida por Balsadi (2000), cujos procedimentos básicos são os seguintes: obtenção dos indicadores simples; construção dos índices parciais, a partir das médias aritméticas dos indicadores simples, no sentido de captar as dimensões da qualidade do emprego; cálculo do IQE, a partir das médias aritméticas dos índices parciais.

Serão descritos a seguir os indicadores simples e os índices parciais para as quatro dimensões selecionadas para avaliar a evolução da qualidade do emprego na agricultura no período 2001-2004: nível educacional dos empregados; grau de formalidade do emprego; rendimento recebido no trabalho principal; e auxílios recebidos pelos empregados.

Para analisar o nível educacional das pessoas empregadas foram selecionados indicadores relacionados a dois aspectos: alfabetização e nível de escolaridade. Para isso, foram escolhidos os seguintes indicadores simples: \% de pessoas empregadas não analfabetas ou com mais de um ano de estudo (INDALF); \% de pessoas ocupadas com até quatro anos de estudo (INDESC1); \% de pessoas ocupadas com oito ou mais anos de estudo (INDESC2). Assim, o índice parcial de educação foi calculado da seguinte forma: INDEDUC $=$ (INDALF + INDESC1 + INDESC2) $/ 3$.

$\mathrm{Na}$ formalidade do emprego, foram selecionados: \% de empregados com idade acima de 15 anos (NINF), o que representa a proporção de trabalhadores não infantis empregada; \% de empregados com jornada semanal de até 44 horas (JORN), o que corresponde à participação dos empregados sem sobretrabalho; \% de empregados com carteira assinada (CART); \% de empregados contribuintes da Previdência Social (PREV). Assim, o índice parcial do grau de formalidade foi calculado da seguinte maneira: INDFORMAL $=(\mathrm{NINF}+\mathrm{JORN}+\mathrm{CART}+\mathrm{PREV}) / 4$.

Para o rendimento obtido no trabalho principal foram seleciona- 
das a \% de empregados com remuneração acima de um salário mínimo (NPOB) e o rendimento médio mensal (REND). Assim, o índice parcial de rendimento foi calculado da seguinte forma: INDREND = $(\mathrm{NPOB}+\mathrm{REND}) / 2$.

Nos auxílios recebidos foram selecionados: \% de empregados que recebiam auxílio moradia (AUXMOR); \% de empregados que recebiam auxílio alimentação (AUXALIM); \% de empregados que recebiam auxílio transporte (AUXTRANS); \% de empregados que recebiam auxílio educação (AUXEDUC); \% de empregados que recebiam auxílio saúde (AUXSAU). Assim, o índice parcial de auxílios recebidos foi calculado da seguinte forma: INDAUX $=($ AUXMOR + AUXALIM + AUXTRANS + AUXEDUC + AUXSAU) $/ 5$.

De todos esses indicadores selecionados, apenas o rendimento médio mensal precisou ser padronizado para variar de 0 a 100, segundo a fórmula: ((valor - mínimo)/(máximo - mínimo)), onde o mínimo e o máximo são, respectivamente, os valores mínimo e máximo do rendimento encontrados em toda a série, possibilitando a comparação intertemporal.

Vale salientar que antes de ser feita a padronização, os rendimentos médios de 2001 e 2004 foram corrigidos para setembro de 2005, por meio do INPC, do IBGE. A escolha desse índice de preços deu-se pelo fato de que ele é obtido para famílias com renda na faixa de um a oito salários mínimos, o que é muito mais próximo da realidade das famílias dos empregados na agricultura brasileira.

De forma resumida, o Índice de Qualidade do Emprego (IQE) foi calculado da seguinte forma: IQE = (INDEDUC + INDFORMAL + INDREND + INDAUX) $/ 4$.

O IQE, assim obtido, é passível de comparação intertemporal. Para essa comparação, trabalhou-se com a idéia de progresso relativo, calculado pela fórmula:

\section{valor do índice em t1 - valor em t0 \\ 100 - valor em t0}

O denominador mostra o máximo crescimento que seria possível a partir do ano inicial (progresso possível) e o numerador indica o crescimento obtido de fato no período considerado (progresso efetivo). A razão entre os dois valores compreende a velocidade relativa da melhoria nas condições e qualidade do emprego (KAGEYAMA; REHDER, 1993). 


\section{Resultados e Discussão}

\subsection{Os Dados para o Total de Brasil}

Os dados da Tabela 8 confirmam, no nível agregado para o Brasil, a hipótese inicial. Ou seja, todas as categorias de empregados registraram melhorias na qualidade do emprego, medida pelo IQE proposto.

Tabela 8 - Índice de Qualidade do Emprego (IQE) dos Empregados Permanentes e dos Empregados Temporários - Brasil, 2001-2004

\begin{tabular}{|c|c|c|c|c|c|c|c|c|}
\hline \multirow{3}{*}{$\begin{array}{c}\text { Índices Parciais } \\
\text { e IQE }\end{array}$} & \multicolumn{4}{|c|}{ Empregado Permanente } & \multicolumn{4}{|c|}{ Empregado Temporário } \\
\hline & \multicolumn{2}{|c|}{ Urbano } & \multicolumn{2}{|c|}{ Rural } & \multicolumn{2}{|c|}{ Urbano } & \multicolumn{2}{|c|}{ Rural } \\
\hline & 2001 & 2004 & 2001 & 2004 & 2001 & 2004 & 2001 & 2004 \\
\hline INDEDUC & 41,9 & 43,5 & 42,0 & 42,8 & 37,8 & 40,6 & 41,1 & 40,7 \\
\hline INDFORMAL & 53,2 & 59,0 & 55,2 & 58,3 & 39,3 & 42,7 & 37,5 & 39,4 \\
\hline INDRENDA & 52,5 & 55,7 & 46,4 & 47,1 & 29,3 & 31,5 & 15,8 & 19,2 \\
\hline INDAUX & 20,2 & 21,7 & 23,0 & 23,5 & 13,7 & 13,5 & 9,5 & 9,6 \\
\hline IQE & 42,0 & 45,0 & 41,7 & 42,9 & 30,0 & 32,1 & 25,9 & 27,2 \\
\hline
\end{tabular}

Fonte: Elaboração do Autor a partir dos microdados da PNAD.

Com exceção dos índices parciais de educação para os empregados temporários rurais e de auxílios para os empregados temporários urbanos, que tiveram pequeno recuo, todos os demais índices apresentaram progresso relativo positivo, indicando algum tipo de melhoria. Embora deva ser ressaltado que ainda prevalecem condições muito mais favoráveis para os empregados permanentes, em relação aos temporários. Esses resultados são determinados, mais fortemente, pelos componentes vinculados ao grau de formalidade do emprego (carteira assinada e contribuição previdenciária, principalmente), ao rendimento médio mensal e a alguns benefícios recebidos. Por isso, é importante fazer uma análise um pouco mais detalhada do IQE e dos seus índices parciais.

Primeiramente, é importante olhar para os índices parciais de modo a identificar quais deles mais contribuíram para a melhoria do IQE. Pelos dados da Tabela 9, que apresenta o progresso relativo para o período 2001-2004, e da Tabela 1 do Anexo Estatístico, que traz todos os indicadores simples utilizados no cálculo do IQE, o índice parcial de formalidade foi o mais relevante para todas as categorias, com exce- 
ção dos empregados temporários com residência rural, para os quais o índice parcial de renda foi o que apresentou maior progresso (o de formalidade ficou em segundo lugar - aliás, foram os dois únicos com relevância para esta categoria).

Tabela 9 - Progresso Relativo do IQE dos Empregados Permanentes e dos Empregados Temporários - Brasil, 2001-2004

\begin{tabular}{|c|c|c|c|c|}
\hline \multirow{3}{*}{$\begin{array}{l}\text { Índices Parci- } \\
\text { ais e IQE }\end{array}$} & \multicolumn{2}{|c|}{ Empregado Permanente } & \multicolumn{2}{|c|}{ Empregado Temporário } \\
\hline & Urbano & Rural & Urbano & Rural \\
\hline & $\%$ & $\%$ & $\%$ & $\%$ \\
\hline INDEDUC & \multicolumn{2}{|c|}{2,8} & \multicolumn{2}{|c|}{4,4} \\
\hline INDFORMAL & \multicolumn{2}{|c|}{12,3} & \multicolumn{2}{|c|}{5,6} \\
\hline INDRENDA & \multicolumn{2}{|c|}{6,7} & \multicolumn{2}{|c|}{3,1} \\
\hline INDAUX & \multicolumn{2}{|c|}{1,8} & \multicolumn{2}{|c|}{$-0,1$} \\
\hline IQE & \multicolumn{2}{|c|}{5,2} & & 1,8 \\
\hline
\end{tabular}

Fonte: Elaboração do Autor a partir dos microdados da PNAD.

Dentro do índice parcial que mede o grau de formalidade do emprego, merecem destaque o aumento da participação dos empregados com carteira assinada e com contribuição para a Previdência Social, que são fatores cruciais para a aposentadoria (urbana e rural), que tem se constituído em política social de caráter universal da maior importância para o bem-estar dos idosos no Brasil, especialmente daqueles residentes nas regiões menos desenvolvidas ${ }^{3}$.

Apesar de todas as categorias terem registrado aumento nesses indicadores de formalidade, é muito distante a realidade dos empregados temporários daquela observada para os empregados permanentes. Enquanto os temporários rurais e urbanos tiveram apenas $4,8 \%$ e $14,2 \%$, respectivamente, de carteira assinada em 2004, os permanentes rurais e urbanos tiveram $49,6 \%$ e $50,0 \%$, respectivamente. Para a contribuição previdenciária, o quadro foi muito semelhante (Tabela 1 do Anexo Estatístico).

Embora os temporários rurais tenham registrado seu maior progresso relativo no índice parcial de renda no período 2001-2004, seus ga-

\footnotetext{
${ }^{3}$ Sobre a importância dos benefícios da aposentadoria, especialmente da aposentadoria rural, ver os trabalhos de Delgado (1997) e Delgado; Cardoso Jr. (1999).
} 
nhos continuam muito distantes das demais categorias. Em 2004, eles recebiam, em média, $\mathrm{R} \$ 194,45$ (preços reais de setembro de 2005), contra $\mathrm{R}$ \$ 279,05 dos temporários urbanos, $\mathrm{R}$ \$ 359,35 dos permanentes rurais e $\mathrm{R} \$ 425,95$ dos permanentes urbanos.

No outro extremo, o índice parcial relacionado aos auxílios recebidos pelos empregados (moradia, alimentação, transporte, educação e saúde) foi o que teve menor impacto nas melhorias registradas pelo IQE. Quanto aos demais, eles se alternaram em importância: o índice parcial de educação foi mais relevante para os permanentes rurais e para os temporários urbanos, ao passo que o índice de renda foi mais importante para os permanentes urbanos e para os temporários rurais.

Para finalizar esse item, apenas mais alguns comentários sobre o IQE e seus índices parciais:

- os empregados permanentes urbanos, que possuem o melhor IQE, foram também os que apresentaram o maior progresso relativo no período $(5,2 \%)$, enquanto os empregados temporários rurais, que possuem o pior IQE, foram os que tiveram o menor progresso relativo (1,8\%).

- no índice parcial de educação merecem destaque positivo: o aumento da participação dos empregados alfabetizados ou com mais de um ano de estudo (ou seja, os empregados não analfabetos) em todas as categorias; e o aumento da participação dos empregados com oito anos ou mais de estudo em todas as categorias, com destaque para os permanentes urbanos; fatos que compensaram a redução dos empregados com até quatro anos de estudo.

- no índice parcial de formalidade também houve melhoria na participação dos empregados com jornada regular de até 44 horas semanais e na redução do trabalho infantil, cuja maior participação, em 2004, foi de $4,1 \%$ entre os temporários rurais.

- no índice parcial de renda, os valores observados para a participação de empregados recebendo mais de um salário mínimo por mês não apresentaram desempenho tão significativo, embora tais participações ainda sejam muito discrepantes entre as categorias: em 2004, 27,7\% dos temporários rurais recebiam mais de um salário mínimo mensal, contra $38,2 \%$ dos temporários urbanos, $56,1 \%$ dos permanentes rurais e $62,4 \%$ dos permanentes urbanos.

- ainda no índice parcial de renda, vale destacar o aumento real 
dos rendimentos médios mensais de todas as categorias no período 2001-2004: 6,0\% para os permanentes urbanos; 4,2\% para os permanentes rurais; $11,6 \%$ para os temporários urbanos; e 12,3\% para os temporários rurais, que apesar desse ganho ainda continuam recebendo menos da metade do que recebem os permanentes urbanos (Tabela 1 do Anexo Estatístico).

- para o índice parcial de auxílios recebidos, vale reforçar que ele apresentou progresso relativo muito baixo no período 2001-2004, e também que: o auxílio moradia, como era de se esperar, é o mais relevante para os empregados permanentes com residência rural, seguido pelo auxílio alimentação; os auxílios moradia, alimentação e transporte têm participações relativamente próximas para os permanentes urbanos; os auxílios alimentação e transporte são os mais relevantes para os temporários urbanos; o auxílio alimentação é o mais importante para os temporários rurais; o auxílio educação é inexpressivo em todas as categorias e o auxílio saúde têm maior relevância para os empregados permanentes (urbanos e rurais).

\subsection{Os Dados para as Culturas}

Neste item, o intuito é tecer alguns breves comentários sobre o comportamento do IQE para as seis culturas selecionadas: arroz, café, canade-açúcar, mandioca, milho e soja. A relevância disso reside no fato de se fazer uma melhor qualificação da análise da qualidade do emprego na agricultura, saindo do nível mais agregado das categorias para um nível mais detalhado, que são as culturas. Além disso, será possível verificar as diferenças de comportamento do IQE entre as próprias culturas, umas "mais modernizadas e de comércio exterior", outras "menos modernizadas e de comércio interno”.

\subsubsection{Arroz}

Inicialmente, vale ressaltar que todas as categorias de empregados ocupados na cultura do arroz apresentaram melhorias no IQE no período 2001-2004, como pode ser visto na Tabela 10. O grande destaque na cultura do arroz foi a melhoria no IQE dos empregados permanentes 
rurais, que apresentou um progresso relativo de 23,0\% no período, o maior entre todas as culturas selecionadas. Quem mais se aproximou deste desempenho foi o IQE dos empregados permanentes urbanos ocupados na cultura da soja, que teve um progresso relativo de $19,5 \%$.

Tabela 10 - Índice de Qualidade do Emprego (IQE) dos Empregados Permanentes e dos Empregados Temporários

Cultura do Arroz - Brasil, 2001-2004

\begin{tabular}{|c|c|c|c|c|c|c|c|c|}
\hline \multirow{3}{*}{$\begin{array}{c}\text { Índices Parciais } \\
\text { e IQE }\end{array}$} & \multicolumn{4}{|c|}{ Empregado Permanente } & \multicolumn{4}{|c|}{ Empregado Temporário } \\
\hline & \multicolumn{2}{|c|}{ Urbano } & \multicolumn{2}{|c|}{ Rural } & \multicolumn{2}{|c|}{ Urbano } & \multicolumn{2}{|c|}{ Rural } \\
\hline & 2001 & 2004 & 2001 & 2004 & 2001 & 2004 & 2001 & 2004 \\
\hline INDEDUC & 44,5 & 47,3 & 37,1 & 43,8 & 30,2 & 35,9 & 40,9 & 40,3 \\
\hline INDFORMAL & 51,7 & 56,4 & 48,4 & 60,6 & 43,0 & 39,4 & 45,7 & 43,6 \\
\hline INDRENDA & 61,1 & 58,4 & 53,2 & 85,8 & 11,0 & 19,5 & 7,6 & 9,3 \\
\hline INDAUX & 18,1 & 25,9 & 19,2 & 23,4 & 14,9 & 14,9 & 8,5 & 11,5 \\
\hline IQE & 43,9 & 47,0 & 39,5 & 53,4 & 24,7 & 27,4 & 25,7 & 26,2 \\
\hline
\end{tabular}

Fonte: Elaboração do Autor a partir dos microdados da PNAD.

Pode-se notar, pelos dados da Tabela 11, que os permanentes rurais ocupados na cultura do arroz tiveram progresso relativo significativo em todos os índices parciais do IQE, com destaque para o grau de formalidade $(23,6 \%)$ e o de renda $(69,6 \%)$. No índice de formalidade, os principais avanços foram na redução do trabalho infantil (ausente em 2004), e no aumento da participação dos empregados com carteira assinada e com contribuição para a Previdência Social, que registrou valores de 57,1\% e 59,9\%, respectivamente, em 2004 (Tabela 2 do Anexo Estatístico).

No índice parcial de renda, o grande destaque foi o aumento real dos rendimentos médios mensais, que passaram de $\mathrm{R} \$ 404,83$, em 2001, para R \$ 647,23, em 2004, ou seja, um ganho de 59,9\%. Com isso, a porcentagem de empregados que ganhavam mais de um salário mínimo subiu de $60,9 \%$ para $86,1 \%$.

A segunda categoria com maior progresso relativo no IQE foi a dos empregados permanentes urbanos (5,5\%). Apesar da redução de 7,0\% no índice parcial de renda, motivada, principalmente, pela queda real de 5,4\% no valor do rendimento médio mensal, o desempenho positivo dos demais índices parciais acabou por compensar aquela queda no cálculo final do IQE. 
Ainda para os permanentes urbanos merecem destaque: o aumento da participação dos empregados com até quatro anos de estudo e dos empregados com oito anos ou mais de estudo, que tiveram impacto positivo no índice parcial de educação; a melhoria no indicador simples relacionado à jornada semanal regular, que influenciou o resultado do índice parcial de formalidade; a significativa melhoria no índice de auxílios recebidos (progresso relativo de 9,6\%), com aumento de todos eles (Tabela 2 do Anexo Estatístico).

Tabela 11 - Progresso Relativo do IQE dos Empregados Permanentes e dos Empregados Temporários - Cultura do Arroz - Brasil, 2001-2004

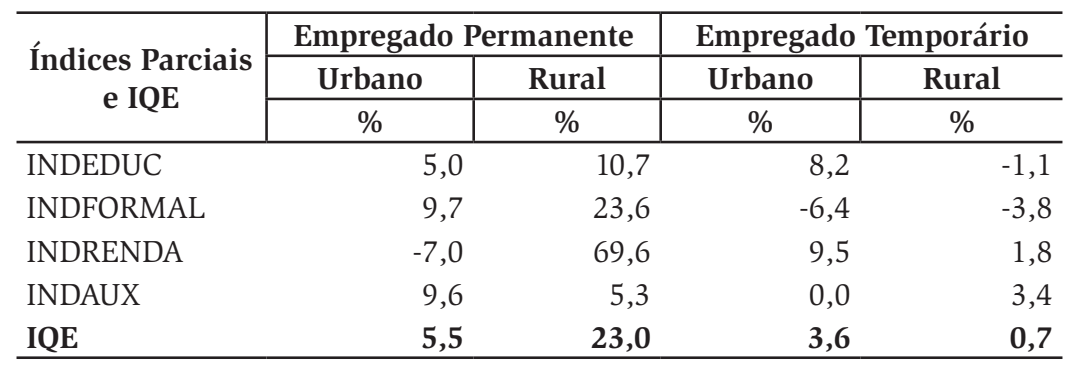

Fonte: Elaboração do Autor a partir dos microdados da PNAD.

Os empregados temporários, que já possuíam os menores IQEs, tiveram os menores progressos relativos no período, especialmente os temporários rurais (apenas 0,7\%). Para estes, o ganho real de 14,4\% no rendimento médio mensal e a melhoria no recebimento de alguns benefícios, principalmente alimentação e saúde, foram os fatores que permitiram o pequeno crescimento do IQE. Já para os temporários urbanos, que tiveram um progresso de $3,6 \%$, os melhores desempenhos foram para os índices de educação $(8,2 \%)$ e de renda $(9,5 \%)$, com destaque para o aumento da participação dos empregados alfabetizados e dos empregados com oito ou mais anos de estudo, além do aumento dos empregados que recebiam mais de um salário mínimo e do ganho real de $22,1 \%$ no rendimento médio mensal no período 2001-2004. Os demais índices, ou ficaram estagnados (benefícios) ou sofreram queda (formalidade). 


\subsubsection{Café}

Com base nas Tabelas 12 e 13, são feitas duas observações iniciais que diferenciam um pouco o comportamento do IQE na cultura do café, em relação ao que foi analisado até o momento: primeiro, não foram todas as categorias que tiveram melhorias no IQE; segundo, os maiores progressos relativos do período foram verificados para os empregados temporários (urbanos e rurais). No entanto, é preciso dizer que isso não alterou o quadro de melhores condições de emprego para os empregados permanentes, que ainda possuem os maiores IQEs.

Os empregados permanentes rurais tiveram redução de 1,7\% no progresso relativo do IQE, a qual foi motivada pelas quedas verificadas em todos os índices parciais, com exceção daquele relacionado com o grau de formalidade.

A melhoria no IQE do empregados temporários, 8,2\% para os urbanos e 5,0\% para os rurais, foi decorrência dos progressos verificados nos índices de educação, formalidade e renda. No nível educacional, houve aumento importante da participação dos empregados alfabetizados e, também, dos empregados com oito anos ou mais de estudo (Tabela 3 do Anexo Estatístico).

Tabela 12 - Índice de Qualidade do Emprego (IQE) dos Empregados Permanentes e dos Empregados Temporários - Cultura do Café - Brasil, 2001-2004

\begin{tabular}{|c|c|c|c|c|c|c|c|c|}
\hline \multirow{3}{*}{$\begin{array}{c}\text { Índices Parciais } \\
\text { e IQE }\end{array}$} & \multicolumn{4}{|c|}{ Empregado Permanente } & \multicolumn{4}{|c|}{ Empregado Temporário } \\
\hline & \multicolumn{2}{|c|}{ Urbano } & \multicolumn{2}{|c|}{ Rural } & \multicolumn{2}{|c|}{ Urbano } & \multicolumn{2}{|c|}{ Rural } \\
\hline & 2001 & 2004 & 2001 & 2004 & 2001 & 2004 & 2001 & 2004 \\
\hline INDEDUC & 43,2 & 44,3 & 46,3 & 45,0 & 40,5 & 44,6 & 41,0 & 44,3 \\
\hline INDFORMAL & 62,6 & 69,2 & 58,5 & 59,5 & 42,2 & 54,6 & 43,9 & 48,1 \\
\hline INDRENDA & 44,2 & 43,7 & 38,6 & 36,7 & 24,4 & 29,4 & 11,5 & 18,8 \\
\hline INDAUX & 12,2 & 14,3 & 22,0 & 20,3 & 9,5 & 11,4 & 7,6 & 7,8 \\
\hline IQE & 40,5 & 42,9 & 41,4 & 40,4 & 29,2 & 35,0 & 26,0 & 29,7 \\
\hline
\end{tabular}

Fonte: Elaboração do Autor a partir dos microdados da PNAD.

No índice parcial que mede o grau de formalidade, o principal destaque foi o aumento dos empregados temporários com carteira assinada e com contribuição previdenciária. Entre os urbanos, os valores para esses indicadores passaram de 14,3\%, em 2001, para 32,6, em 2004. Já 
para os rurais, os valores foram de 3,8\%, em 2001, e 12,7\%, em 2004 . Com relação aos rendimentos, houve tanto aumento da participação dos empregados que recebiam mais de um salário mínimo por mês, como ganho real nos rendimentos médios mensais: $13,4 \%$ para os temporários urbanos e $14,5 \%$ para os temporários rurais.

Finalmente, os empregados permanentes urbanos, que tiveram progresso relativo de 4,0\% no IQE. Com exceção da queda no índice parcial de renda, os demais tiveram progresso relativo positivo, com grande destaque para o grau de formalidade do emprego (17,7\%). Nesse índice, o destaque foi o aumento da participação dos empregados com carteira assinada e contribuintes da Previdência Social, que passou de 54,3\%, em 2001, para $63,2 \%$, em 2004. Ainda merecem destaque o aumento importante dos empregados permanentes urbanos com oito anos ou mais de estudo ocupados na cultura do café e o crescimento dos empregados que recebiam o auxílio saúde (Tabela 3 do Anexo Estatístico).

Tabela 13 - Progresso Relativo do IQE dos Empregados Permanentes e dos Empregados Temporários - Cultura do Café - Brasil, 2001-2004

\begin{tabular}{|c|c|c|c|c|}
\hline \multirow{3}{*}{$\begin{array}{c}\text { Índices } \\
\text { Parciais e IQE }\end{array}$} & \multicolumn{2}{|c|}{ Empregado Permanente } & \multicolumn{2}{|c|}{ Empregado Temporário } \\
\hline & Urbano & Rural & Urbano & Rural \\
\hline & $\%$ & $\%$ & $\%$ & $\%$ \\
\hline INDEDUC & 2,0 & $-2,4$ & 6,8 & $\overline{5,6}$ \\
\hline INDFORMAL & 17,7 & 2,3 & 21,5 & 7,5 \\
\hline INDRENDA & $-0,8$ & $-3,2$ & 6,6 & 8,3 \\
\hline INDAUX & 2,4 & $-2,2$ & 2,1 & 0,2 \\
\hline IQE & 4,0 & $-1,7$ & 8,2 & 5,0 \\
\hline
\end{tabular}

Fonte: Elaboração do Autor a partir dos microdados da PNAD.

\subsubsection{Cana-de-Açúcar}

A partir dos dados das Tabelas 14 e 15, é possível observar que todas as categorias de empregados na cultura da cana-de-açúcar tiveram aumento do IQE, e que o maior progresso relativo foi para os temporários rurais $(5,2 \%)$. Mas, o fato que talvez chame mais a atenção é a grande diferença nos valores do IQE entre os residentes urbanos e rurais, na mesma condição de ocupação. Isto é, os permanentes urbanos têm um IQE muito maior do que os permanentes rurais, enquanto os temporários urbanos têm um IQE bem maior do que os temporários rurais. 
Tabela 14 - Índice de Qualidade do Emprego (IQE) dos Empregados Permanentes e dos Empregados Temporários Cultura da Cana-de-Açúcar - Brasil, 2001-2004

\begin{tabular}{l|c|c|c|c|c|c|c|c}
\hline \multirow{2}{*}{\begin{tabular}{c} 
Índices Parciais \\
\multirow{2}{*}{ e IQE }
\end{tabular}} & \multicolumn{3}{|c|}{ Empregado Permanente } & \multicolumn{3}{c}{ Empregado Temporário } \\
\cline { 2 - 10 } & \multicolumn{2}{|c|}{ Urbano } & \multicolumn{2}{c}{ Rural } & \multicolumn{2}{c|}{ Urbano } & \multicolumn{2}{c}{ Rural } \\
\cline { 2 - 10 } & $\mathbf{2 0 0 1}$ & $\mathbf{2 0 0 4}$ & $\mathbf{2 0 0 1}$ & $\mathbf{2 0 0 4}$ & $\mathbf{2 0 0 1}$ & $\mathbf{2 0 0 4}$ & $\mathbf{2 0 0 1}$ & $\mathbf{2 0 0 4}$ \\
\hline INDEDUC & 43,5 & 42,4 & 26,8 & 29,8 & 40,6 & 42,7 & 33,7 & 33,7 \\
INDFORMAL & 79,6 & 81,7 & 69,7 & 67,7 & 65,7 & 68,4 & 51,8 & 57,4 \\
INDRENDA & 61,7 & 61,5 & 35,3 & 37,4 & 47,0 & 48,6 & 19,7 & 25,0 \\
INDAUX & 17,6 & 23,7 & 18,5 & 21,1 & 17,6 & 15,3 & 10,8 & 14,9 \\
IQE & $\mathbf{5 0 , 6}$ & $\mathbf{5 2 , 3}$ & $\mathbf{3 7 , 6}$ & $\mathbf{3 9 , 0}$ & $\mathbf{4 2 , 7}$ & $\mathbf{4 3 , 7}$ & $\mathbf{2 9 , 0}$ & $\mathbf{3 2 , 7}$ \\
\hline
\end{tabular}

Fonte: Elaboração do Autor a partir dos microdados da PNAD.

Além disso, também chama a atenção o fato do IQE dos temporários urbanos ser melhor do que o IQE dos permanentes rurais, evidenciando a importância das lutas históricas dos trabalhadores canavieiros, principalmente no Estado de São Paulo4, que é o maior produtor nacional.

O aumento do IQE dos temporários rurais foi muito influenciado pelo progresso relativo verificado no índice parcial ligado ao grau de formalidade $(11,6 \%)$. Dentro desse índice, houve redução do trabalho infantil (participação de apenas 0,8\% em 2004), aumento do número de empregados com carteira assinada (de 26,8\%, em 2001, para $39,7 \%$, em 2004) e aumento dos contribuintes para a Previdência (de $28,2 \%$, em 2001, para 42,8\% em 2004). Quanto aos índices de renda e auxílios, os principais avanços foram no ganho real do rendimento médio mensal, que foi de $20,9 \%$ no período, e no aumento do recebimento de alguns benefícios, especialmente os de moradia e transportes (Tabela 4 do Anexo Estatístico).

As melhorias no grau de formalidade também foram as mais relevantes para o progresso relativo de 1,7\% no IQE dos temporários urbanos. O IQE desses empregados, como já foi salientado, é maior do que o IQE dos permanentes urbanos, em 2001 e 2004, pelos melhores indicadores ligados aos índices de educação e de renda. No nível educacional, é bem maior a participação dos empregados temporários urbanos alfabetizados, em relação aos permanentes rurais $(76,0 \%$,

\footnotetext{
${ }^{4}$ Sobre esse tema, ver o importante trabalho de Graziano da Silva (1997).
} 
em 2004, contra 50,4\%). No tocante aos rendimentos, é maior o rendimento médio mensal dos temporários urbanos - R \$394,25, em 2004, contra R\$330,17 dos permanentes rurais. Em função disso, também há maior participação dos empregados que recebiam mais de um salário mínimo entre os temporários urbanos (53,3\%, em 2004, contra 41,6\% dos permanentes rurais).

Para os empregados permanentes urbanos, que possuem um dos maiores IQEs entre as culturas selecionadas, o progresso relativo de $3,4 \%$ foi muito influenciado pelo desempenho dos índices de formalidade $(10,6 \%)$ e de auxílios $(7,4 \%)$. Na questão da formalidade, chama a atenção o elevadíssimo percentual de empregados com carteira assinada e com contribuição previdenciária: 93,0\% e 93,4\%, respectivamente, em 2004. Certamente, a cultura da cana-de-açúcar é uma das atividades da agricultura brasileira com maior nível de formalidade do emprego, em todas as categorias de empregados (permanentes e temporários, urbanos e rurais) ${ }^{5}$. Nos auxílios recebidos, merecem destaque o aumento de participação em todos eles, e a significativa importância do auxílio saúde (18,8\%, em 2004), outro diferenciador da cana-deaçúcar em relação às demais culturas (Tabela 4 do Anexo Estatístico).

Tabela 15 - Progresso Relativo do IQE dos Empregados Permanentes e dos Empregados Temporários - Cultura da Cana-de-Açúcar - Brasil, 2001-2004

\begin{tabular}{|c|c|c|c|c|}
\hline \multirow{3}{*}{$\begin{array}{c}\text { Índices Parciais } \\
\text { e IQE }\end{array}$} & \multicolumn{2}{|c|}{ Empregado Permanente } & \multicolumn{2}{|c|}{ Empregado Temporário } \\
\hline & Urbano & Rural & Urbano & Rural \\
\hline & $\%$ & $\%$ & $\%$ & $\%$ \\
\hline INDEDUC & \multicolumn{2}{|c|}{$-2,0$} & 3,5 & 0,0 \\
\hline INDFORMAL & 10,6 & $-6,5$ & 7,7 & 11,6 \\
\hline INDRENDA & $-0,5$ & 3,2 & 2,9 & 6,6 \\
\hline INDAUX & 7,4 & 3,2 & $-2,7$ & 4,6 \\
\hline IQE & 3,4 & 2,2 & 1,7 & 5,2 \\
\hline
\end{tabular}

Fonte: Elaboração do Autor a partir dos microdados da PNAD.

\footnotetext{
${ }^{5}$ Segundo dados da PNAD, 32,3\% dos empregados na agricultura brasileira tinham carteira assinada em 2004. Para os empregados permanentes urbanos ocupados na cultura da cana-de-açúcar, esse valor, no mesmo ano, foi de 93,0\%. Para os permanentes rurais, temporários urbanos e temporários rurais, os valores foram, respectivamente: $64,9 \%$, $66,8 \%$ e $39,7 \%$. Ou seja, os temporários rurais ocupados na cana-de-açúcar têm um nível de formalidade maior do que a média da agricultura nacional.
} 


\subsubsection{Mandioca}

Para a cultura da mandioca, valem dois comentários iniciais: seus empregados possuem IQEs que estão entre os mais baixos dentre as culturas selecionadas; apenas os empregados temporários tiveram progresso relativo positivo no período 2001-2004 (Tabelas 16 e 17). Mesmo assim, só para os temporários urbanos que o crescimento foi significativo $(6,3 \%)$.

O aumento do IQE dos temporários urbanos foi determinado pelos progressos verificados nos índices parciais de educação (principalmente), formalidade e renda. No índice de educação, todos os indicadores registraram melhorias, pois aumentou a participação dos empregados alfabetizados, dos empregados com até quatro anos de estudo e dos empregados com oito anos ou mais de estudo (Tabela 5 do Anexo Estatístico).

Tabela 16 - Índice de Qualidade do Emprego (IQE) dos Empregados Permanentes e dos Empregados Temporários

Cultura da Mandioca - Brasil, 2001-2004

\begin{tabular}{|c|c|c|c|c|c|c|c|c|}
\hline \multirow{3}{*}{$\begin{array}{c}\text { Índices } \\
\text { Parciais e IQE }\end{array}$} & \multicolumn{4}{|c|}{ Empregado Permanente } & \multicolumn{4}{|c|}{ Empregado Temporário } \\
\hline & \multicolumn{2}{|c|}{ Urbano } & \multicolumn{2}{|c|}{ Rural } & \multicolumn{2}{|c|}{ Urbano } & \multicolumn{2}{|c|}{ Rural } \\
\hline & 2001 & 2004 & 2001 & 2004 & 2001 & 2004 & 2001 & 2004 \\
\hline INDEDUC & 38,5 & 36,1 & 34,1 & 36,9 & 30,7 & 41,3 & 29,9 & 32,0 \\
\hline INDFORMAL & 34,8 & 42,5 & 47,1 & 45,5 & 36,3 & 41,5 & 41,1 & 42,6 \\
\hline INDRENDA & 31,0 & 21,4 & 19,3 & 12,6 & 10,9 & 15,6 & 1,9 & 3,5 \\
\hline INDAUX & 19,5 & 14,0 & 11,2 & 8,2 & 7,0 & 6,6 & 4,6 & 3,2 \\
\hline IQE & 30,9 & 28,5 & 28,0 & 25,8 & 21,2 & 26,2 & 19,4 & 20,3 \\
\hline
\end{tabular}

Fonte: Elaboração do Autor a partir dos microdados da PNAD.

Tabela 17 - Progresso Relativo do IQE dos Empregados Permanentes e dos Empregados Temporários - Cultura da Mandioca - Brasil, 2001-2004

\begin{tabular}{|c|c|c|c|c|}
\hline \multirow{3}{*}{$\begin{array}{l}\text { Índices Parci- } \\
\text { ais e IQE }\end{array}$} & \multicolumn{2}{|c|}{ Empregado Permanente } & \multicolumn{2}{|c|}{ Empregado Temporário } \\
\hline & Urbano & Rural & Urbano & Rural \\
\hline & $\%$ & $\%$ & $\%$ & $\%$ \\
\hline INDEDUC & \multicolumn{2}{|c|}{$-3,9$} & 15,4 & 3,1 \\
\hline INDFORMAL & \multicolumn{2}{|c|}{11,9} & \multicolumn{2}{|c|}{8,1} \\
\hline INDRENDA & \multicolumn{2}{|c|}{$-14,0$} & \multicolumn{2}{|c|}{5,3} \\
\hline INDAUX & \multicolumn{2}{|c|}{$-6,8$} & \multicolumn{2}{|c|}{$-0,4$} \\
\hline IQE & \multicolumn{2}{|c|}{$-3,5$} & 6 & 1,1 \\
\hline
\end{tabular}

Fonte: Elaboração do Autor a partir dos microdados da PNAD. 
No grau de formalidade, o único avanço foi na melhoria da jornada de trabalho regular, pois os demais indicadores não sofreram alteração. Em 2004, 70,7\% dos temporários urbanos tiveram jornada de até 44 horas semanais (em 2001, eram 49,2\%). No extremo oposto da cana-de-açúcar, a cultura da mandioca certamente está entre as atividades da agricultura brasileira com os menores índices de formalidade do emprego.

O pequeno progresso relativo observado para os temporários rurais $(1,1 \%)$ foi impulsionado por alguns indicadores: no nível educacional, pelo aumento da participação dos empregados alfabetizados; no grau de formalidade, pela redução do trabalho infantil e pela melhoria na jornada regular de trabalho; na renda, pelo ganho real de 16,9\% no rendimento médio mensal. Ainda no tocante ao rendimento médio mensal, vale destacar que os temporários rurais ocupados na cultura da mandioca registraram, em 2004, o segundo menor valor recebido pelos empregados nas culturas selecionadas, $\mathrm{R} \$ 150,55$ (valores reais de setembro de 2005). O pior rendimento foi verificado para os temporários rurais ocupados na cultura do arroz, R $\$ 149,12$.

Quanto aos empregados permanentes, urbanos e rurais, pode-se observar que tiveram queda no valor do IQE, de 3,5\% e 3,1\%, respectivamente, contribuindo, assim, para que a cultura da mandioca registrasse pouquíssimos avanços, em termos gerais, na qualidade do emprego. Com isso, percebe-se que, diferentemente das demais culturas, não há diferenças gritantes de IQE entre os empregados permanentes e os temporários, nem entre os residentes urbanos e rurais. Ou seja, há um "nivelamento por baixo” nas condições de emprego nessa atividade.

\subsubsection{Milho}

Apesar de relativamente modestos, houve progressos no IQE de todas as categorias de empregados na cultura do milho (Tabelas 18 e 19). Outro detalhe importante é que, apesar de possuírem melhor qualidade do emprego, as distâncias dos IQEs dos empregados permanentes não chega a ser extremamente elevada em relação aos IQEs dos empregados temporários. 
Tabela 18 - Índice de Qualidade do Emprego (IQE) dos Empregados Permanentes e dos Empregados Temporários - Cultura do Milho - Brasil, 2001-2004

\begin{tabular}{|c|c|c|c|c|c|c|c|c|}
\hline \multirow{3}{*}{$\begin{array}{c}\text { Índices } \\
\text { Parciais e IQE }\end{array}$} & \multicolumn{4}{|c|}{ Empregado Permanente } & \multicolumn{4}{|c|}{ Empregado Temporário } \\
\hline & \multicolumn{2}{|c|}{ Urbano } & \multicolumn{2}{|c|}{ Rural } & \multicolumn{2}{|c|}{ Urbano } & \multicolumn{2}{|c|}{ Rural } \\
\hline & 2001 & 2004 & 2001 & 2004 & 2001 & 2004 & 2001 & 2004 \\
\hline INDEDUC & 44,0 & 38,6 & 37,1 & 41,4 & 36,9 & 39,3 & 39,6 & 41,0 \\
\hline INDFORMAL & 49,8 & 50,8 & 43,6 & 47,4 & 38,6 & 41,5 & 38,9 & 42,4 \\
\hline INDRENDA & 33,8 & 40,2 & 26,3 & 23,4 & 14,4 & 21,0 & 5,5 & 4,1 \\
\hline INDAUX & 14,1 & 18,8 & 14,3 & 17,5 & 7,5 & 7,2 & 5,5 & 7,9 \\
\hline IQE & 35,4 & 37,1 & 30,3 & 32,4 & 24,4 & 27,2 & 22,4 & 23,9 \\
\hline
\end{tabular}

Fonte: Elaboração do Autor a partir dos microdados da PNAD.

Para os permanentes urbanos, vale a pena destacar o aumento real de $26,7 \%$ no rendimento médio mensal, que impactou positivamente o progresso do índice parcial de renda, e o aumento no recebimento dos auxílios moradia, educação e saúde, que resultaram nos avanços verificados para o índice parcial de auxílios. Como destaque negativo, é importante citar a forte redução do índice de educação (-9,6\%), devido ao fraco desempenho de todos os indicadores a ele ligados (alfabetização e nível de escolaridade).

Tabela 19 - Progresso Relativo do IQE dos Empregados Permanentes e dos Empregados Temporários - Cultura do Milho - Brasil, 2001-2004

\begin{tabular}{|c|c|c|c|c|}
\hline \multirow{3}{*}{$\begin{array}{c}\text { Índices } \\
\text { Parciais e IQE }\end{array}$} & \multicolumn{2}{|c|}{ Empregado Permanente } & \multicolumn{2}{|c|}{ Empregado Temporário } \\
\hline & Urbano & Rural & Urbano & Rural \\
\hline & $\%$ & $\%$ & $\%$ & $\%$ \\
\hline INDEDUC & \multicolumn{2}{|c|}{$-9,6$} & \multicolumn{2}{|c|}{3,8} \\
\hline INDFORMAL & \multicolumn{2}{|c|}{2,0} & \multicolumn{2}{|c|}{4,6} \\
\hline INDRENDA & \multicolumn{2}{|c|}{9,6} & \multicolumn{2}{|c|}{7,7} \\
\hline INDAUX & \multicolumn{2}{|c|}{5,5} & \multicolumn{2}{|c|}{$-0,3$} \\
\hline IQE & \multicolumn{2}{|c|}{2,6} & \multicolumn{2}{|c|}{3,7} \\
\hline
\end{tabular}

Fonte: Elaboração do Autor a partir dos microdados da PNAD.

Os permanentes rurais tiveram um progresso de 3,0\% no seu IQE devido, principalmente, aos avanços nos índices parciais de educação e de grau de formalidade. No nível educacional, houve aumentos nas participações dos empregos alfabetizados e dos empregados com até quatro anos de estudo. Quanto ao grau de formalidade, os destaques 
foram a redução do trabalho infantil (ausente em 2004) e a melhoria na jornada de trabalho regular, já que nos itens carteira assinada e contribuição para a Previdência Social não houve avanços. Nos auxílios recebidos, pode-se mencionar o aumento daqueles ligados à moradia $\mathrm{e}$ à alimentação (Tabela 6 do Anexo Estatístico).

O progresso relativo de 3,7\% registrado para o IQE dos temporários urbanos foi influenciado pelos progressos verificados nos seguintes indicadores: ganho real de $13,3 \%$ no rendimento médio mensal e aumento da participação dos empregados que ganhavam mais de um salário mínimo, no índice de renda; aumento da participação dos empregados alfabetizados e com mais de um ano de estudo, no nível educacional; pequena melhoria em todos os indicadores ligados ao índice de formalidade (redução do trabalho infantil, melhoria na jornada regular de trabalho, aumento dos empregados com carteira assinada e contribuintes previdenciários).

Finalmente, no modesto progresso relativo $(1,9 \%)$ do IQE dos temporários rurais pode-se ressaltar o avanço de 5,8\% no índice ligado ao grau de formalidade do emprego. Nesse índice, os destaques foram a redução do trabalho infantil e o aumento da participação dos empregados com jornada regular (72,7\%, em 2004, contra 57,8\%, em 2001). Além da queda no índice de renda, vale registrar que os temporários rurais tiveram, em 2004, o terceiro menor rendimento médio mensal entre os empregados nas culturas selecionadas, R\$ 156,60 (Tabela 6 do Anexo Estatístico).

\subsubsection{Soja}

A cultura da soja também ficou entre aquelas nas quais houve aumentos no IQE de todas categorias de empregados. Trata-se de uma cultura que apresenta diferenças muito perceptíveis entre a qualidade do emprego dos empregados permanentes e dos temporários. É evidente, pelos dados da Tabela 20, que o IQE dos empregados permanentes, urbanos e rurais, está entre os mais altos dentre as culturas selecionadas no presente estudo. 
Tabela 20 - Índice de Qualidade do Emprego (IQE) dos Empregados Permanentes e dos Empregados Temporários - Cultura da Soja - Brasil, 2001-2004

\begin{tabular}{l|c|c|c|c|c|c|c|c}
\hline \multirow{2}{*}{$\begin{array}{c}\text { Índices } \\
\text { Parciais e IQE }\end{array}$} & \multicolumn{3}{|c|}{ Empregado Permanente } & \multicolumn{3}{c}{ Empregado Temporário } \\
\cline { 2 - 9 } & \multicolumn{2}{|c|}{ Urbano } & \multicolumn{2}{c}{ Rural } & \multicolumn{2}{c}{ Urbano } & \multicolumn{2}{c}{ Rural } \\
\cline { 2 - 9 } & $\mathbf{2 0 0 1}$ & $\mathbf{2 0 0 4}$ & $\mathbf{2 0 0 1}$ & $\mathbf{2 0 0 4}$ & $\mathbf{2 0 0 1}$ & $\mathbf{2 0 0 4}$ & $\mathbf{2 0 0 1}$ & $\mathbf{2 0 0 4}$ \\
\hline INDEDUC & 41,8 & 50,7 & 48,1 & 47,7 & 45,0 & 41,7 & 27,7 & 43,3 \\
INDFORMAL & 56,4 & 61,4 & 59,7 & 61,3 & 34,8 & 35,8 & 29,7 & 31,2 \\
INDRENDA & 68,5 & 95,6 & 80,4 & 80,3 & 42,8 & 52,1 & 27,0 & 33,0 \\
INDAUX & 26,5 & 26,0 & 27,9 & 29,4 & 14,7 & 23,7 & 20,1 & 14,5 \\
IQE & $\mathbf{4 8 , 3}$ & $\mathbf{5 8 , 4}$ & $\mathbf{5 4 , 0}$ & $\mathbf{5 4 , 7}$ & $\mathbf{3 4 , 3}$ & $\mathbf{3 8 , 3}$ & $\mathbf{2 6 , 1}$ & $\mathbf{3 0 , 5}$ \\
\hline
\end{tabular}

Fonte: Elaboração do Autor a partir dos microdados da PNAD.

Chama a atenção, inicialmente, o elevado progresso relativo do IQE dos empregados permanentes urbanos (19,5\%). E, dentro do IQE, o grande progresso no índice parcial de renda $(86,1 \%)$, seguido dos índices de educação $(15,3 \%)$ e de formalidade $(11,5 \%)$.

No índice de renda, houve um aumento real de $41,4 \%$ no rendimento médio mensal dos permanentes urbanos. Com isso, em 2004, 91,3\% dos empregados recebiam mais de um salário mínimo por mês. No nível educacional, os destaques positivos foram o grande aumento da participação dos empregados alfabetizados (de $74,7 \%$, em 2001, para 92,6\%, em 2004) e o crescimento dos empregados com oito ou mais anos de estudo (de 5,0\%, em 2001, para 15,1\%, em 2004). Quanto ao grau de formalidade, houve aumento de 59,0\%, em 2001, para 62,9\%, em 2004 , na participação dos empregados com registro em carteira e com contribuição para a Previdência Social (Tabela 7 do Anexo Estatístico).

Tabela 21 - Progresso Relativo do IQE dos Empregados Permanentes e dos Empregados Temporários - Cultura da Soja - Brasil, 2001-2004

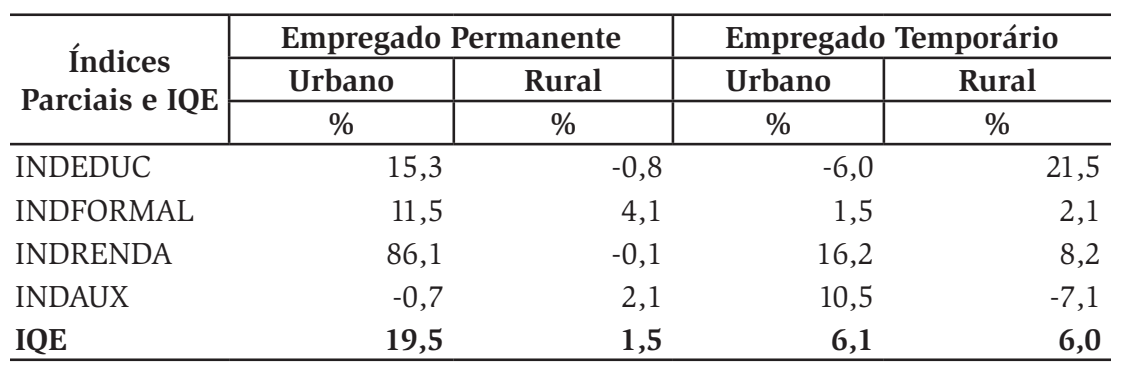

Fonte: Elaboração do Autor a partir dos microdados da PNAD. 
Os empregados permanentes rurais, praticamente, tiveram um IQE estável no período. A melhoria no grau de formalidade $(4,1 \%)$ ocorreu pela melhoria na jornada regular de trabalho. Mesmo assim, é importante destacar que, em 2004, apenas 20,0\% dos empregados trabalhavam até 44 horas semanais, o que indica um fortíssimo grau de sobretrabalho na cultura da soja (e isso vale para todas as categorias de empregados).

Os temporários urbanos, por sua vez, registraram um progresso relativo de $6,1 \%$, que foi determinado, basicamente, pelos avanços nos índices parciais de renda $(16,2 \%)$ e de auxílios recebidos (10,5\%). Nos indicadores de renda, apesar da queda real de $13,2 \%$ no rendimento médio mensal, houve aumento importante dos empregados que recebiam mais de um salário mínimo (65,2\%, em 2004, contra 37,5\%, em 2001). Nos auxílios, destaque para os aumentos nos quesitos alimentação, transporte e saúde (Tabela 7 do Anexo Estatístico).

Para os temporários rurais, o progresso de 6,0\% no IQE foi garantido especialmente pelo desempenho dos índices parciais de educação $(21,5 \%)$ e de renda $(8,2 \%)$. Na questão educacional, registrou-se importante aumento da participação dos empregados alfabetizados e com oito anos ou mais de estudo, cujos valores foram, respectivamente, $81,4 \%$ e $21,9 \%$, em 2004. Quanto ao índice de renda, houve ganho real de $20,6 \%$ no rendimento médio mensal e aumento dos empregados que recebiam mais de um salário mínimo.

\subsection{O Ranking para o IQE}

Feitas as análises do IQE para o total de Brasil e para as seis culturas selecionadas, pode-se fazer um ranking dos índices obtidos, de modo a se saber qual atividade apresentou, dentro dos limites metodológicos adotados, a melhor qualidade do emprego agrícola. Esse ranking, feito com base no ano de 2004, é apresentado na Tabela 22. Para complementar o ranking, são reapresentados os dados relativos ao rendimento médio mensal dos empregados permanentes e temporários no período 2001-2004, bem como sua variação real.

Pode-se notar que a cultura da soja foi a que apresentou os melhores IQEs, com os empregados permanentes urbanos e rurais. A seguir vieram os empregados permanentes rurais ocupados na cultura do ar- 
roz, os empregados permanentes urbanos ocupados na cultura da canade-açúcar e os empregados permanentes urbanos ocupados na cultura do arroz. Essas cinco categorias ficaram acima do melhor IQE agregado para o Brasil, que foi o dos empregados permanentes urbanos.

No outro extremo, as seis categorias com IQE abaixo do pior IQE agregado para o Brasil, que foi para os empregados temporários rurais, foram as seguintes: empregado temporário urbano ocupado na cultura do milho; empregado temporário rural ocupado na cultura do arroz; empregado temporário urbano ocupado na cultura da mandioca; empregado permanente rural ocupado na cultura da mandioca; empregado temporário rural ocupado na cultura do milho; empregado temporário rural ocupado na cultura da mandioca.

Ou seja, os dados obtidos para o IQE mostram claramente que as melhores condições de emprego estavam, de forma geral, nas culturas "mais dinâmicas e de comércio exterior" e para os empregados permanentes, em 2004. Entre os dez melhores IQEs (excluindo-se os valores agregados para o total de Brasil - ou seja, ficando-se apenas com as culturas), oito são para empregados permanentes (quatro urbanos e quatro rurais) e apenas dois para empregados temporários (ambos urbanos), três são para a cultura da soja, três também para a cultura da cana-de-açúcar, dois para o café e dois para o arroz.

Por outro lado, entre os dez piores IQEs, oito são para empregados temporários (cinco rurais e três urbanos) e apenas dois para empregados permanentes (um rural e um urbano), quatro são para a cultura da mandioca, dois para o arroz, dois para o milho, um para o café e um para a cultura da soja.

\section{Conclusões}

Em função do cenário bastante favorável para a agricultura, também marcado pelo aumento do número de empregados (e dos empregados formais) no período 2001-2004, o presente estudo procurou analisar a evolução da qualidade do emprego nesse importante segmento econômico. Para isso foi proposto, construído e calculado um Índice de Qualidade do Emprego (IQE), composto por quatro dimensões: nível educacional dos empregados; grau de formalidade do emprego; rendimento no trabalho principal; e auxílios recebidos pelos empregados. 
Tabela 22 - Índice de Qualidade do Emprego (IQE), Progresso Relativo e Rendimento Médio Mensal dos Empregados Permanentes e dos Empregados Temporários - Brasil e Culturas, 2001-2004

\begin{tabular}{|c|c|c|c|c|c|c|}
\hline \multirow[t]{2}{*}{ Categorias } & \multicolumn{2}{|l|}{ IQE } & \multirow{2}{*}{\begin{tabular}{|c|}
$\begin{array}{c}\text { Prog. } \\
\text { Relativo } \\
2001-04 \\
(\%)\end{array}$ \\
\end{tabular}} & \multicolumn{2}{|c|}{\begin{tabular}{|c|} 
Rend. Médio \\
(R\$)
\end{tabular}} & \multirow{2}{*}{\begin{tabular}{|c} 
Variação \\
$2001-04$ \\
$(\%)$
\end{tabular}} \\
\hline & 2001 & 2004 & & 2001 & 2004 & \\
\hline Empregado Permanente Urbano - Soja & 48,3 & 58,4 & 19,5 & 519,75 & 735,19 & 41,5 \\
\hline Empregado Permanente Rural - Soja & 54,0 & 54,7 & 1,5 & 564,34 & 581,77 & 3,1 \\
\hline Empregado Permanente Rural - Arroz & 39,5 & 53,4 & 23,0 & 404,83 & 647,23 & 59,9 \\
\hline Empregado Permanente Urbano - Cana & 50,6 & 52,3 & 3,4 & 433,72 & 452,12 & 4,2 \\
\hline Empregado Permanente Urbano - Arroz & 43,9 & 47,0 & 5,5 & 432,26 & 408,95 & $-5,4$ \\
\hline Empregado Permanente Urbano - Brasil & 42,0 & 45,0 & 5,2 & 401,82 & 425,95 & 6,0 \\
\hline Empregado Temporário Urbano - Cana & 42,7 & 43,7 & 1,7 & 357,79 & 394,25 & 10,2 \\
\hline Empregado Permanente Rural - Brasil & 41,7 & 42,9 & 2,1 & 344,84 & 359,35 & 4,2 \\
\hline Empregado Permanente Urbano - Café & 40,5 & 42,9 & 4,0 & 358,30 & 335,57 & $-6,3$ \\
\hline Empregado Permanente Rural - Café & 41,4 & 40,4 & $-1,7$ & 315,66 & 312,00 & $-1,2$ \\
\hline Empregado Permanente Rural - Cana & 37,6 & 39,0 & 2,2 & 293,78 & 330,17 & 12,4 \\
\hline Empregado Temporário Urbano - Soja & 34,3 & 38,3 & 6,1 & 420,50 & 364,79 & $-13,2$ \\
\hline Empregado Permanente Urbano - Milho & 35,4 & 37,1 & 2,6 & 279,11 & 353,73 & 26,7 \\
\hline Empregado Temporário Urbano - Café & 29,2 & 35,0 & 8,2 & 244,66 & 277,54 & 13,4 \\
\hline Empregado Temporário Rural - Cana & 29,0 & 32,7 & 5,2 & 226,97 & 274,34 & 20,9 \\
\hline Empregado Permanente Rural - Milho & 30,3 & 32,4 & 3,0 & 265,47 & 253,91 & $-4,4$ \\
\hline Empregado Temporário Urbano - Brasil & 30,0 & 32,1 & 3,0 & 250,07 & 279,05 & 11,6 \\
\hline Empregado Temporário Rural - Soja & 26,1 & 30,5 & 6,0 & 228,73 & 275,88 & 20,6 \\
\hline Empregado Temporário Rural - Café & 26,0 & 29,7 & 5,0 & 191,84 & 219,64 & 14,5 \\
\hline Empregado Permanente Urbano - Mandioca & 30,9 & 28,5 & $-3,5$ & 227,24 & 232,69 & 2,4 \\
\hline Empregado Temporário Urbano - Arroz & 24,7 & 27,4 & 3,6 & 160,69 & 196,26 & 22,1 \\
\hline Empregado Temporário Rural - Brasil & 25,9 & 27,2 & 1,8 & 173,16 & 194,45 & 12,3 \\
\hline Empregado Temporário Urbano - Milho & 24,4 & 27,2 & 3,7 & 191,10 & 216,59 & 13,3 \\
\hline Empregado Temporário Rural - Arroz & 25,7 & 26,2 & 0,7 & 130,37 & 149,12 & 14,4 \\
\hline Empregado Temporário Urbano - Mandioca & 21,2 & 26,2 & 6,3 & 177,04 & 216,26 & 22,2 \\
\hline Empregado Permanente Rural - Mandioca & 28,0 & 25,8 & $-3,1$ & 238,51 & 210,31 & $-11,8$ \\
\hline Empregado Temporário Rural - Milho & 22,4 & 23,9 & 1,9 & 141,32 & 156,60 & 10,8 \\
\hline Empregado Temporário Rural - Mandioca & 19,4 & 20,3 & 1,1 & 128,77 & 150,55 & 16,9 \\
\hline
\end{tabular}

Fonte: Elaboração do Autor a partir dos Microdados da PNAD.

Os principais resultados obtidos podem ser assim sintetizados:

- Os IQEs obtidos comprovaram a hipótese inicial, evidenciando a melhoria geral nos dados agregados para o Brasil. No entanto, 
houve diferenciações importantes por categoria de empregado e por cultura.

- Um fato preocupante é que os empregados permanentes urbanos, que possuem o melhor IQE, foram também os que apresentaram o maior progresso relativo no período $(5,2 \%)$, enquanto os empregados temporários rurais, que possuem o pior IQE, foram os que tiveram o menor progresso relativo $(1,8 \%)$.

- Apesar dos avanços no IQE dos empregados temporários, a situação dos empregados permanentes é muito melhor: entre os dez melhores IQEs obtidos para as culturas, oito são para empregados permanentes e apenas dois para empregados temporários; já entre os dez piores IQEs a situação é inversa, pois oito são para empregados temporários e apenas dois para empregados permanentes.

- Entre os empregados temporários com melhor qualidade do emprego, destaque para aqueles ocupados nas culturas do café e da canade-açúcar, para os quais foram muito relevantes os avanços obtidos nas lutas dos trabalhadores para contratos de trabalho mais dignos.

- Os IQEs obtidos para as culturas selecionadas evidenciaram um cenário bem melhor para os empregados nas atividades "mais dinâmicas e de comércio exterior”. Em 2004, entre os dez melhores IQEs, três são para a cultura da soja, três para a cultura da cana-de-açúcar, dois para o café e dois para o arroz. Neste mesmo ano, os dois melhores IQEs foram para a cultura da soja (com os empregados permanentes urbanos e rurais), que registrou enorme expansão da área cultivada e da produção no período analisado.

No período 2001-2004, a categoria de empregados representou, em média, 27,8\% do total dos ocupados na agricultura brasileira. Para eles, o cenário favorável verificado no setor refletiu-se em avanços, mesmo que modestos em alguns casos, nas condições de trabalho. Como o processo não foi homogêneo para todas as categorias de empregados e culturas analisadas, restam como maiores desafios a melhoria nas condições de emprego para os empregados temporários, urbanos e rurais, que continuam com elevados níveis de precarização, e para as culturas de "mercado interno", predominantemente. As commodities internacionais propiciaram melhores condições de trabalho, especialmente para os seus empregados permanentes. 


\section{Referências bibliográficas}

BALSADI, O.V. Comportamento das Ocupações na Agropecuária Brasileira no Período 1999-2003. IEA, São Paulo, Informações Econômicas, 2005, vol.35, n.9, setembro, p:38-49.

BALSADI, O.V. Características do Emprego Rural no Estado de São Paulo nos Anos 90. Campinas, IE - Unicamp, 2000, Dissertação de Mestrado.

BRANDÃO, A.S.P.; REZENDE, G.C. de; MARQUES, R.W. da C. Crescimento Agrícola no Período 1999-2004, Explosão da Área Plantada com Soja e Meio Ambiente no Brasil. Ipea, Rio de Janeiro, Texto para Discussão n.1062, janeiro de 2005, 21p.

DELGADO, G.C. Previdência Rural: relatório de avaliação socioeconômica. Ipea, Brasília, Texto para Discussão n.477, 1997.

DELGADO, G.C.; CARDOSO JR., J.C. O Idoso e a Previdência Rural no Brasil: a experiência recente da universalização. Ipea, Brasília, Texto para Discussão n.688, dezembro de 1999.

GASQUEZ, J.G.; BASTOS, E.T.; BACCHI, M.P.R.; CONCEIÇÃO, J.C.P.R. Condicionantes da Produtividade da Agricultura Brasileira. Ipea, Brasília, Texto para Discussão n.1017, abril de 2004, 30p.

GASQUEZ, J.G.; REZENDE, G.C. de; VILLA VERDE, C.M.; SALERNO, M.S.; CONCEIÇÃO, J.C.P.R.; CARVALHO, J.C. de S. Desempenho e Crescimento do Agronegócio no Brasil. Ipea, Brasília, Texto para Discussão n.1009, fevereiro de 2004, 40p.

GRAZIANO DA SILVA, J. De Bóias-Frias a Empregados Rurais - as greves dos canavieiros paulistas de Guariba e de Leme. Alagoas, EDUFAL, 1997.

INSTITUTO BRASILEIRO DE GEOGRAFIA E ESTATÍSTICA (IBGE). Pesquisa Nacional por Amostra de Domicílios, v.24, Rio de Janeiro, 2004, 27p.

KAGEYAMA, A.; REHDER, P. O Bem-Estar Rural no Brasil na Década de Oitenta. Revista de Economia e Sociologia Rural. Brasília, v. 31, n.1, jan/mar. 1993, p.23-44. 


\section{Anexo Estatístico}

Tabela 1 - Índice de Qualidade do Emprego (IQE) dos Empregados Permanentes e dos Empregados Temporários, Brasil, 2001-2004

\begin{tabular}{|c|c|c|c|c|c|c|c|c|}
\hline \multirow{3}{*}{$\begin{array}{c}\text { Índices } \\
\text { Parciais e IQE }\end{array}$} & \multicolumn{4}{|c|}{ Empregado Permanente } & \multicolumn{4}{|c|}{ Empregado Temporário } \\
\hline & \multicolumn{2}{|c|}{ Urbano } & \multicolumn{2}{|c|}{ Rural } & \multicolumn{2}{|c|}{ Urbano } & \multicolumn{2}{|c|}{ Rural } \\
\hline & 2001 & 2004 & 2001 & 2004 & 2001 & 2004 & 2001 & 2004 \\
\hline Indalf & 73,2 & 77,7 & 73,2 & 76,4 & 65,8 & 73,1 & 69,3 & 73,0 \\
\hline Indesc1 & 44,9 & 39,6 & 47,7 & 45,4 & 44,2 & 42,7 & 50,0 & 44,0 \\
\hline Indesc 2 & 7,7 & 13,3 & 5,1 & 6,6 & 3,6 & 5,9 & 3,9 & 5,0 \\
\hline INDEDUC & 41,9 & 43,5 & 42,0 & 42,8 & 37,8 & 40,6 & 41,1 & 40,7 \\
\hline Ninf & 98,0 & 98,0 & 97,6 & 98,6 & 96,1 & 96,3 & 93,6 & 95,9 \\
\hline Jorn & 32,1 & 37,3 & 32,1 & 34,6 & 38,4 & 45,7 & 50,0 & 51,8 \\
\hline Cart & 41,2 & 50,0 & 44,9 & 49,6 & 11,1 & 14,2 & 2,9 & 4,8 \\
\hline Prev & 41,7 & 50,6 & 46,1 & 50,4 & 11,7 & 14,6 & 3,3 & 5,2 \\
\hline INDFORMAL & 53,2 & 59,0 & 55,2 & 58,3 & 39,3 & 42,7 & 37,5 & 39,4 \\
\hline Npob & 60,0 & 62,4 & 57,2 & 56,1 & 38,6 & 38,2 & 24,2 & 27,7 \\
\hline Rend (1) & 401,82 & 425,95 & 344,84 & 359,35 & 250,07 & 279,05 & 173,16 & 194,45 \\
\hline Rendp & 45,0 & 49,0 & 35,6 & 38,0 & 20,0 & 24,8 & 7,3 & 10,8 \\
\hline INDRENDA & 52,5 & 55,7 & 46,4 & 47,1 & 29,3 & 31,5 & 15,8 & 19,2 \\
\hline Auxmor & 26,6 & 26,3 & 71,5 & 68,6 & 12,3 & 10,7 & 12,7 & 13,4 \\
\hline Auxalim & 38,3 & 40,4 & 29,9 & 31,8 & 25,8 & 26,7 & 27,0 & 23,3 \\
\hline Auxtrans & 27,0 & 33,9 & 8,1 & 10,1 & 27,9 & 28,5 & 6,2 & 9,1 \\
\hline Auxeduc & 1,0 & 0,9 & 0,5 & 1,1 & 0,3 & 0,2 & 0,2 & 0,2 \\
\hline Auxsau & 8,1 & 6,9 & 5,1 & 6,1 & 2,0 & 1,6 & 1,1 & 2,3 \\
\hline INDAUX & 20,2 & 21,7 & 23,0 & 23,5 & 13,7 & 13,5 & 9,5 & 9,6 \\
\hline IQE & 42,0 & 45,0 & 41,7 & 42,9 & 30,0 & 32,1 & 25,9 & 27,2 \\
\hline
\end{tabular}

Fonte: Elaboração do Autor a partir dos microdados da PNAD.

(1) Valores em Reais, corrigidos para setembro de 2005 pelo INPC do IBGE. 
Tabela 2 - Índice de Qualidade do Emprego (IQE) dos Empregados Permanentes e dos Empregados Temporários, Cultura do Arroz, Brasil, 2001-2004

\begin{tabular}{|c|c|c|c|c|c|c|c|c|}
\hline \multirow{3}{*}{$\begin{array}{c}\text { Índices } \\
\text { Parciais e IQE }\end{array}$} & \multicolumn{4}{|c|}{ Empregado Permanente } & \multicolumn{4}{|c|}{ Empregado Temporário } \\
\hline & \multicolumn{2}{|c|}{ Urbano } & \multicolumn{2}{|c|}{ Rural } & \multicolumn{2}{|c|}{ Urbano } & \multicolumn{2}{|c|}{ Rural } \\
\hline & 2001 & 2004 & 2001 & 2004 & 2001 & 2004 & 2001 & 2004 \\
\hline Indalf & 91,9 & 84,8 & 66,2 & 94,3 & 53,6 & 66,2 & 63,9 & 72,5 \\
\hline Indesc1 & 39,1 & 52,0 & 42,6 & 32,8 & 37,0 & 36,9 & 58,9 & 48,3 \\
\hline Indesc 2 & 2,6 & 5,1 & 2,5 & 4,4 & 0,0 & 4,6 & 0,0 & 0,0 \\
\hline INDEDUC & 44,5 & 47,3 & 37,1 & 43,8 & 30,2 & 35,9 & 40,9 & 40,3 \\
\hline Ninf & 100,0 & 100,0 & 97,5 & 100,0 & 100,0 & 96,0 & 100,0 & 95,5 \\
\hline Jorn & 18,0 & 33,8 & 27,4 & 25,2 & 60,3 & 58,0 & 82,7 & 69,4 \\
\hline Cart & 44,5 & 45,9 & 34,3 & 57,1 & 5,9 & 1,7 & 0,0 & 4,8 \\
\hline Prev & 44,5 & 45,9 & 34,3 & 59,9 & 5,9 & 1,7 & 0,0 & 4,8 \\
\hline INDFORMAL & 51,7 & 56,4 & 48,4 & 60,6 & 43,0 & 39,4 & 45,7 & 43,6 \\
\hline Npob & 72,2 & 70,6 & 60,9 & 86,1 & 16,7 & 27,8 & 15,0 & 15,2 \\
\hline Rend (1) & 432,26 & 408,95 & 404,83 & 647,23 & 160,69 & 196,26 & 130,37 & 149,12 \\
\hline Rendp & 50,0 & 46,2 & 45,5 & 85,5 & 5,3 & 11,1 & 0,3 & 3,4 \\
\hline INDRENDA & 61,1 & 58,4 & 53,2 & 85,8 & 11,0 & 19,5 & 7,6 & 9,3 \\
\hline Auxmor & 32,7 & 52,7 & 53,8 & 62,4 & 16,5 & 19,2 & 9,6 & 11,3 \\
\hline Auxalim & 36,7 & 39,4 & 37,1 & 42,1 & 43,7 & 45,2 & 27,7 & 38,8 \\
\hline Auxtrans & 21,0 & 29,7 & 4,9 & 9,5 & 14,0 & 9,5 & 5,0 & 4,4 \\
\hline Auxeduc & 0,0 & 2,2 & 0,0 & 0,0 & 0,0 & 0,0 & 0,0 & 0,0 \\
\hline Auxsau & 0,0 & 5,7 & 0,0 & 3,2 & 0,0 & 0,7 & 0,0 & 3,2 \\
\hline INDAUX & 18,1 & 25,9 & 19,2 & 23,4 & 14,9 & 14,9 & 8,5 & 11,5 \\
\hline IQE & 43,9 & 47,0 & 39,5 & 53,4 & 24,7 & 27,4 & 25,7 & 26,2 \\
\hline
\end{tabular}

Fonte: Elaboração do Autor a partir dos microdados da PNAD.

(1) Valores em Reais, corrigidos para setembro de 2005 pelo INPC do IBGE. 
Tabela 3 - Índice de Qualidade do Emprego (IQE) dos Empregados Permanentes e dos Empregados Temporários, Cultura do Café, Brasil, 2001-2004

\begin{tabular}{|c|c|c|c|c|c|c|c|c|}
\hline \multirow{3}{*}{$\begin{array}{c}\text { Índices } \\
\text { Parciais e IQE }\end{array}$} & \multicolumn{4}{|c|}{ Empregado Permanente } & \multicolumn{4}{|c|}{ Empregado Temporário } \\
\hline & \multicolumn{2}{|c|}{ Urbano } & \multicolumn{2}{|c|}{ Rural } & \multicolumn{2}{|c|}{ Urbano } & \multicolumn{2}{|c|}{ Rural } \\
\hline & 2001 & 2004 & 2001 & 2004 & 2001 & 2004 & 2001 & 2004 \\
\hline$\overline{\text { Indalf }}$ & 73,4 & 77,8 & 77,7 & 79,9 & 69,5 & 81,1 & 68,2 & 77,6 \\
\hline Indesc1 & 51,0 & 44,5 & 57,6 & 48,1 & 50,0 & 44,1 & 51,0 & 48,4 \\
\hline Indesc2 & 5,0 & 10,7 & 3,7 & 7,0 & 2,1 & 8,6 & 3,7 & 6,9 \\
\hline INDEDUC & 43,2 & 44,3 & 46,3 & 45,0 & 40,5 & 44,6 & 41,0 & 44,3 \\
\hline Ninf & 100,0 & 99,2 & 98,7 & 98,1 & 96,4 & 98,6 & 92,8 & 98,6 \\
\hline Jorn & 41,7 & 51,3 & 46,1 & 46,9 & 43,7 & 54,8 & 75,3 & 68,5 \\
\hline Cart & 54,3 & 63,2 & 43,5 & 46,0 & 14,3 & 32,6 & 3,8 & 12,7 \\
\hline Prev & 54,3 & 63,2 & 45,8 & 46,9 & 14,5 & 32,6 & 3,8 & 12,7 \\
\hline INDFORMAL & 62,6 & 69,2 & 58,5 & 59,5 & 42,2 & 54,6 & 43,9 & 48,1 \\
\hline Npob & 50,5 & 53,3 & 46,5 & 43,2 & 29,7 & 34,2 & 12,5 & 22,6 \\
\hline Rend (1) & 358,30 & 335,57 & 315,66 & 312,00 & 244,66 & 277,54 & 191,84 & 219,64 \\
\hline Rendp & 37,9 & 34,1 & 30,8 & 30,2 & 19,1 & 24,5 & 10,4 & 15,0 \\
\hline INDRENDA & 44,2 & 43,7 & 38,6 & 36,7 & 24,4 & 29,4 & 11,5 & 18,8 \\
\hline Auxmor & 6,8 & 11,4 & 79,5 & 68,7 & 2,7 & 3,5 & 21,4 & 15,8 \\
\hline Auxalim & 16,2 & 14,7 & 20,5 & 26,8 & 5,2 & 3,3 & 6,4 & 6,0 \\
\hline Auxtrans & 34,0 & 38,1 & 6,9 & 2,3 & 38,4 & 49,7 & 8,0 & 17,0 \\
\hline Auxeduc & 0,0 & 0,0 & 0,0 & 0,0 & 0,0 & 0,0 & 1,0 & 0,0 \\
\hline Auxsau & 4,0 & 7,1 & 3,1 & 3,7 & 1,1 & 0,6 & 1,0 & 0,0 \\
\hline INDAUX & 12,2 & 14,3 & 22,0 & 20,3 & 9,5 & 11,4 & 7,6 & 7,8 \\
\hline IQE & 40,5 & 42,9 & 41,4 & 40,4 & 29,2 & 35,0 & 26,0 & 29,7 \\
\hline
\end{tabular}

Fonte: Elaboração do Autor a partir dos microdados da PNAD.

(1) Valores em Reais, corrigidos para setembro de 2005 pelo INPC do IBGE. 
Tabela 4 - Índice de Qualidade do Emprego (IQE) dos Empregados Permanentes e dos Empregados Temporários, Cultura da Cana-de-Açúcar, Brasil, 2001-2004

\begin{tabular}{|c|c|c|c|c|c|c|c|c|}
\hline \multirow{3}{*}{$\begin{array}{c}\text { Índices } \\
\text { Parciais e IQE }\end{array}$} & \multicolumn{4}{|c|}{ Empregado Permanente } & \multicolumn{4}{|c|}{ Empregado Temporário } \\
\hline & \multicolumn{2}{|c|}{ Urbano } & \multicolumn{2}{|c|}{ Rural } & \multicolumn{2}{|c|}{ Urbano } & \multicolumn{2}{|c|}{ Rural } \\
\hline & 2001 & 2004 & 2001 & 2004 & 2001 & 2004 & 2001 & 2004 \\
\hline Indalf & 74,1 & 75,4 & 45,9 & 50,4 & 70,6 & 76,0 & 55,8 & 61,2 \\
\hline Indesc 1 & 49,8 & 40,5 & 31,8 & 33,6 & 48,1 & 46,6 & 43,3 & 36,3 \\
\hline Indesc 2 & 6,6 & 11,3 & 2,8 & 5,5 & 2,9 & 5,4 & 2,0 & 3,6 \\
\hline INDEDUC & 43,5 & 42,4 & 26,8 & 29,8 & 40,6 & 42,7 & 33,7 & 33,7 \\
\hline Ninf & 99,2 & 100,0 & 98,6 & 99,6 & 98,4 & 98,8 & 95,1 & 99,2 \\
\hline Jorn & 37,3 & 40,6 & 48,7 & 41,0 & 35,8 & 38,9 & 56,9 & 47,7 \\
\hline Cart & 90,5 & 93,0 & 65,4 & 64,9 & 63,8 & 66,8 & 26,8 & 39,7 \\
\hline Prev & 91,4 & 93,4 & 66,0 & 65,3 & 64,8 & 68,8 & 28,2 & 42,8 \\
\hline INDFORMAL & 79,6 & 81,7 & 69,7 & 67,7 & 65,7 & 68,4 & 51,8 & 57,4 \\
\hline Npob & 73,1 & 69,6 & 43,4 & 41,6 & 56,3 & 53,3 & 23,2 & 26,0 \\
\hline Rend (1) & 433,72 & 452,12 & 293,78 & 330,17 & 357,79 & 394,25 & 226,97 & 274,34 \\
\hline Rendp & 50,3 & 53,3 & 27,2 & 33,2 & 37,8 & 43,8 & 16,2 & 24,0 \\
\hline INDRENDA & 61,7 & 61,5 & 35,3 & 37,4 & 47,0 & 48,6 & 19,7 & 25,0 \\
\hline Auxmor & 3,3 & 4,8 & 58,7 & 56,8 & 4,8 & 1,0 & 20,8 & 28,1 \\
\hline Auxalim & 12,3 & 26,6 & 2,8 & 10,2 & 9,6 & 7,1 & 6,3 & 8,2 \\
\hline Auxtrans & 58,7 & 66,1 & 27,6 & 29,6 & 65,1 & 58,0 & 21,3 & 37,4 \\
\hline Auxeduc & 0,5 & 2,2 & 1,0 & 0,9 & 0,4 & 0,0 & 0,0 & 0,0 \\
\hline Auxsau & 13,5 & 18,8 & 2,6 & 8,3 & 8,0 & 10,6 & 5,7 & 0,9 \\
\hline INDAUX & 17,6 & 23,7 & 18,5 & 21,1 & 17,6 & 15,3 & 10,8 & 14,9 \\
\hline IQE & 50,6 & 52,3 & 37,6 & 39,0 & 42,7 & 43,7 & 29,0 & 32,7 \\
\hline
\end{tabular}

Fonte: Elaboração do Autor a partir dos microdados da PNAD.

(1) Valores em Reais, corrigidos para setembro de 2005 pelo INPC do IBGE. 
Tabela 5 - Índice de Qualidade do Emprego (IQE) dos Empregados Permanentes e dos Empregados Temporários, Cultura da Mandioca, Brasil, 2001-2004

\begin{tabular}{|c|c|c|c|c|c|c|c|c|}
\hline \multirow{3}{*}{$\begin{array}{c}\text { Índices Parciais } \\
\text { e IQE }\end{array}$} & \multicolumn{4}{|c|}{ Empregado Permanente } & \multicolumn{4}{|c|}{ Empregado Temporário } \\
\hline & \multicolumn{2}{|c|}{ Urbano } & \multicolumn{2}{|c|}{ Rural } & \multicolumn{2}{|c|}{ Urbano } & \multicolumn{2}{|c|}{ Rural } \\
\hline & 2001 & 2004 & 2001 & 2004 & 2001 & 2004 & 2001 & 2004 \\
\hline Indalf & 72,9 & 61,2 & 55,7 & 59,1 & 55,9 & 74,6 & 47,0 & 54,5 \\
\hline Indesc1 & 42,5 & 32,8 & 43,0 & 41,6 & 31,2 & 42,1 & 41,3 & 40,2 \\
\hline Indesc 2 & 0,0 & 14,3 & 3,7 & 10,1 & 4,9 & 7,2 & 1,2 & 1,4 \\
\hline INDEDUC & 38,5 & 36,1 & 34,1 & 36,9 & 30,7 & 41,3 & 29,9 & 32,0 \\
\hline Ninf & 94,3 & 96,5 & 100,0 & 99,1 & 96,2 & 95,4 & 93,0 & 95,1 \\
\hline Jorn & 44,8 & 69,6 & 44,8 & 65,5 & 49,2 & 70,7 & 71,5 & 75,3 \\
\hline Cart & 0,0 & 2,1 & 21,8 & 8,7 & 0,0 & 0,0 & 0,0 & 0,0 \\
\hline Prev & 0,0 & 2,1 & 21,8 & 8,7 & 0,0 & 0,0 & 0,0 & 0,0 \\
\hline INDFORMAL & 34,8 & 42,5 & 47,1 & 45,5 & 36,3 & 41,5 & 41,1 & 42,6 \\
\hline Npob & 45,8 & 25,6 & 20,6 & 11,8 & 13,8 & 16,8 & 3,9 & 3,4 \\
\hline Rend (1) & 227,24 & 232,69 & 238,51 & 210,31 & 177,04 & 216,26 & 128,77 & 150,55 \\
\hline Rendp & 16,2 & 17,1 & 18,1 & 13,4 & 8,0 & 14,4 & 0,0 & 3,6 \\
\hline INDRENDA & 31,0 & 21,4 & 19,3 & 12,6 & 10,9 & 15,6 & 1,9 & 3,5 \\
\hline Auxmor & 22,4 & 16,0 & 43,2 & 22,3 & 7,3 & 3,3 & 3,5 & 2,2 \\
\hline Auxalim & 33,2 & 41,8 & 8,6 & 16,1 & 14,6 & 13,4 & 18,3 & 13,6 \\
\hline Auxtrans & 23,2 & 12,4 & 4,4 & 0,0 & 12,9 & 16,1 & 1,4 & 0,0 \\
\hline Auxeduc & 9,3 & 0,0 & 0,0 & 2,6 & 0,0 & 0,0 & 0,0 & 0,0 \\
\hline Auxsau & 9,3 & 0,0 & 0,0 & 0,0 & 0,0 & 0,0 & 0,0 & 0,0 \\
\hline INDAUX & 19,5 & 14,0 & 11,2 & 8,2 & 7,0 & 6,6 & 4,6 & 3,2 \\
\hline IQE & 30,9 & 28,5 & 28,0 & 25,8 & 21,2 & 26,2 & 19,4 & 20,3 \\
\hline
\end{tabular}

Fonte: Elaboração do Autor a partir dos microdados da PNAD.

(1) Valores em Reais, corrigidos para setembro de 2005 pelo INPC do IBGE. 
Tabela 6 - Índice de Qualidade do Emprego (IQE) dos Empregados Permanentes e dos Empregados Temporários, Cultura do Milho, Brasil, 2001-2004

\begin{tabular}{l|rrrrr|r|r|r|r}
\hline \multirow{2}{*}{ Índices } & \multicolumn{3}{c|}{ Empregado Permanente } & \multicolumn{3}{c}{ Empregado Temporário } \\
\cline { 2 - 9 } & \multicolumn{2}{|c}{ Urbano } & \multicolumn{2}{c}{ Rural } & \multicolumn{2}{c}{ Urbano } & \multicolumn{2}{c}{ Rural } \\
\cline { 2 - 9 } & $\mathbf{2 0 0 1}$ & $\mathbf{2 0 0 4}$ & $\mathbf{2 0 0 1}$ & $\mathbf{2 0 0 4}$ & $\mathbf{2 0 0 1}$ & $\mathbf{2 0 0 4}$ & $\mathbf{2 0 0 1}$ & $\mathbf{2 0 0 4}$ \\
\hline Indalf & 73,6 & 66,0 & 69,6 & 77,1 & 59,1 & 70,8 & 64,5 & 70,6 \\
Indesc1 & 48,8 & 43,3 & 40,8 & 47,2 & 48,8 & 44,6 & 50,8 & 49,8 \\
Indesc2 & 9,6 & 6,7 & 1,0 & 0,0 & 2,9 & 2,6 & 3,4 & 2,7 \\
INDEDUC & $\mathbf{4 4 , 0}$ & $\mathbf{3 8 , 6}$ & $\mathbf{3 7 , 1}$ & $\mathbf{4 1 , 4}$ & $\mathbf{3 6 , 9}$ & $\mathbf{3 9 , 3}$ & $\mathbf{3 9 , 6}$ & $\mathbf{4 1 , 0}$ \\
Ninf & 96,1 & 96,8 & 95,7 & 100,0 & 98,0 & 98,2 & 95,8 & 96,1 \\
Jorn & 39,2 & 42,6 & 29,8 & 46,1 & 48,1 & 55,1 & 57,8 & 72,7 \\
Cart & 31,3 & 30,5 & 24,5 & 20,7 & 3,4 & 5,9 & 0,9 & 0,4 \\
Prev & 32,5 & 33,1 & 24,5 & 23,0 & 5,0 & 6,6 & 1,2 & 0,4 \\
INDFORMAL & $\mathbf{4 9 , 8}$ & $\mathbf{5 0 , 8}$ & $\mathbf{4 3 , 6}$ & $\mathbf{4 7 , 4}$ & $\mathbf{3 8 , 6}$ & $\mathbf{4 1 , 5}$ & $\mathbf{3 8 , 9}$ & $\mathbf{4 2 , 4}$ \\
Npob & 42,9 & 43,2 & 30,0 & 26,1 & 18,6 & 27,6 & 8,9 & 3,7 \\
Rend (1) & 279,11 & 353,73 & 265,47 & 253,91 & 191,10 & 216,59 & 141,32 & 156,60 \\
Rendp & 24,8 & 37,1 & 22,5 & 20,6 & 10,3 & 14,5 & 2,1 & 4,6 \\
INDRENDA & $\mathbf{3 3 , 8}$ & $\mathbf{4 0 , 2}$ & $\mathbf{2 6 , 3}$ & $\mathbf{2 3 , 4}$ & $\mathbf{1 4 , 4}$ & $\mathbf{2 1 , 0}$ & $\mathbf{5 , 5}$ & $\mathbf{4 , 1}$ \\
Auxmor & 15,2 & 28,6 & 46,6 & 52,7 & 5,1 & 2,1 & 4,5 & 5,7 \\
Auxalim & 26,5 & 27,6 & 20,4 & 29,9 & 21,0 & 24,3 & 22,4 & 33,6 \\
Auxtrans & 26,5 & 28,1 & 2,0 & 2,7 & 9,7 & 9,5 & 0,4 & 0,3 \\
Auxeduc & 0,0 & 4,8 & 0,0 & 0,0 & 0,0 & 0,0 & 0,0 & 0,0 \\
Auxsau & 2,2 & 4,8 & 2,7 & 2,2 & 1,6 & 0,0 & 0,3 & 0,0 \\
INDAUX & $\mathbf{1 4 , 1}$ & $\mathbf{1 8 , 8}$ & $\mathbf{1 4 , 3}$ & $\mathbf{1 7 , 5}$ & $\mathbf{7 , 5}$ & $\mathbf{7 , 2}$ & $\mathbf{5 , 5}$ & $\mathbf{7 , 9}$ \\
IQE & $\mathbf{3 5 , 4}$ & $\mathbf{3 7 , 1}$ & $\mathbf{3 0 , 3}$ & $\mathbf{3 2 , 4}$ & $\mathbf{2 4 , 4}$ & $\mathbf{2 7 , 2}$ & $\mathbf{2 2 , 4}$ & $\mathbf{2 3 , 9}$ \\
\hline Fonyyyyyyyyyyy
\end{tabular}

Fonte: Elaboração do Autor a partir dos microdados da PNAD.

(1) Valores em Reais, corrigidos para setembro de 2005 pelo INPC do IBGE. 
Tabela 7 - Índice de Qualidade do Emprego (IQE) dos Empregados Permanentes e dos Empregados Temporários, Cultura da Soja, Brasil, 2001-2004

\begin{tabular}{|c|c|c|c|c|c|c|c|c|}
\hline \multirow{3}{*}{$\begin{array}{c}\text { Índices } \\
\text { Parciais e IQE }\end{array}$} & \multicolumn{4}{|c|}{ Empregado Permanente } & \multicolumn{4}{|c|}{ Empregado Temporário } \\
\hline & \multicolumn{2}{|c|}{ Urbano } & \multicolumn{2}{|c|}{ Rural } & \multicolumn{2}{|c|}{ Urbano } & \multicolumn{2}{|c|}{ Rural } \\
\hline & 2001 & 2004 & 2001 & 2004 & 2001 & 2004 & 2001 & 2004 \\
\hline$\overline{\text { Indalf }}$ & 74,7 & 92,6 & 87,0 & 88,2 & 78,3 & 79,0 & 50,1 & 81,4 \\
\hline Indesc 1 & 45,8 & 44,5 & 48,4 & 39,6 & 51,7 & 36,0 & 33,1 & 26,6 \\
\hline Indesc2 & 5,0 & 15,1 & 8,8 & 15,2 & 4,9 & 10,0 & 0,0 & 21,9 \\
\hline INDEDUC & 41,8 & 50,7 & 48,1 & 47,7 & 45,0 & 41,7 & 27,7 & 43,3 \\
\hline Ninf & 97,7 & 97,1 & 99,0 & 100,0 & 100,0 & 98,2 & 100,0 & 98,1 \\
\hline Jorn & 9,8 & 22,7 & 10,2 & 20,0 & 22,0 & 18,9 & 18,8 & 26,7 \\
\hline Cart & 59,0 & 62,9 & 64,8 & 62,5 & 7,7 & 13,0 & 0,0 & 0,0 \\
\hline Prev & 59,0 & 62,9 & 64,8 & 62,9 & 9,5 & 13,0 & 0,0 & 0,0 \\
\hline INDFORMAL & 56,4 & 61,4 & 59,7 & 61,3 & 34,8 & 35,8 & 29,7 & 31,2 \\
\hline Npob & 72,6 & 91,3 & 88,9 & 86,0 & 37,5 & 65,2 & 37,5 & 41,7 \\
\hline Rend (1) & 519,75 & 735,19 & 564,34 & 581,77 & 420,50 & 364,79 & 228,73 & 275,88 \\
\hline Rendp & 64,5 & 100,0 & 71,8 & 74,7 & 48,1 & 38,9 & 16,5 & 24,3 \\
\hline INDRENDA & 68,5 & 95,6 & 80,4 & 80,3 & 42,8 & 52,1 & 27,0 & 33,0 \\
\hline Auxmor & 30,9 & 26,4 & 82,8 & 78,0 & 19,0 & 23,8 & 27,7 & 23,0 \\
\hline Auxalim & 58,9 & 47,2 & 35,6 & 45,3 & 25,8 & 48,1 & 58,2 & 33,2 \\
\hline Auxtrans & 34,4 & 47,0 & 12,5 & 15,9 & 28,6 & 41,5 & 14,8 & 16,3 \\
\hline Auxeduc & 0,0 & 0,0 & 1,9 & 1,2 & 0,0 & 0,0 & 0,0 & 0,0 \\
\hline Auxsau & 8,3 & 9,4 & 6,5 & 6,7 & 0,0 & 4,9 & 0,0 & 0,0 \\
\hline INDAUX & 26,5 & 26,0 & 27,9 & 29,4 & 14,7 & 23,7 & 20,1 & 14,5 \\
\hline IQE & 48,3 & 58,4 & 54,0 & 54,7 & 34,3 & 38,3 & 26,1 & 30,5 \\
\hline
\end{tabular}

Fonte: Elaboração do Autor a partir dos microdados da PNAD.

(1) Valores em Reais, corrigidos para setembro de 2005 pelo INPC do IBGE.

Recebido em março de 2006 e aprovado em dezembro de 2006 